\title{
Developing structure of two-phase flow in a large diameter pipe at low liquid flow rate
}

$\operatorname{AUTHOR}(S)$ :

Shen, Xiuzhong; Hibiki, Takashi; Nakamura, Hideo

\section{CITATION:}

Shen, Xiuzhong ... [et al]. Developing structure of two-phase flow in a large diameter pipe at low liquid flow rate. International Journal of Heat and Fluid Flow 2012, 34: 70-84

\section{ISSUE DATE:}

2012-04

URL:

http://hdl.handle.net/2433/155564

\section{RIGHT:}

(c) 2012 Elsevier Inc.; This is not the published version. Please cite only the published version.; この論文は出版社版でありません。引用の際に は出版社版をご確認ご利用ください。 
Developing Structure of Two-Phase Flow in a Large Diameter Pipe at Low Liquid Flow Rate

\author{
Xiuzhong Shen ${ }^{\mathrm{a}}$, Takashi Hibiki ${ }^{\mathrm{b}}$, Hideo Nakamura ${ }^{\mathrm{c}}$
}

${ }^{a}$ Research Reactor Institute, Kyoto University, Kumatori-cho, Sennan-gun, Osaka, 590-0494, Japan.

${ }^{\mathrm{b}}$ School of Nuclear Engineering, Purdue University West Lafayette, IN 47907-2017, USA

${ }^{c}$ Nuclear Safety Research Center, Japan Atomic Energy Agency, Tokai-mura, Ibaraki, 319-1195, Japan

\title{
Abstract
}

In order to develop the interfacial area transport equation for the interfacial transfer terms in the two-fluid model, accurate data sets on axial development of local parameters such as void fraction, interfacial area concentration, interfacial gas velocity and Sauter mean diameter are indispensable to verify the modeled source and sink terms in the interfacial area transport equation. From this point of view, local measurements of both Group 1 spherical/distorted bubbles and Group 2 cap/slug bubbles in vertical upward air-water two-phase flow in a large diameter pipe with 200 $\mathrm{mm}$ in inner diameter and $26 \mathrm{~m}$ in height were performed at three axial locations of $\mathrm{z} / \mathrm{D}=41.5,82.8$ and 113 as well as 11 radial locations from $r / R=0-0.95$ by using four-sensor probe method. Here, $z, r, D$ and $R$ are the axial distance from the inlet, radial distance from the pipe center, pipe diameter and pipe radius, respectively. The liquid flow rate and the void fraction ranged from $0.0505 \mathrm{~m} / \mathrm{s}$ to $0.312 \mathrm{~m} / \mathrm{s}$ and from $1.98 \%$ to $32.6 \%$, respectively in the present experiment. The flow condition covered extensive region of bubbly flow, cap turbulent flow as well as their transition. The extensive analysis on the radial profiles of local flow parameters and their axial developments demonstrate the development of interfacial structures along the flow direction due to the bubble coalescence and breakup and the gas expansion. The significant decrease in void faction and interfacial area concentration and the increase in Sauter mean diameter and interfacial velocity were observed when the gradual flow regime transition occurred. Finally, the net change in the interfacial area concentration due to the bubble coalescence and breakup was quantitatively investigated in the present paper to reflect the true transfer mechanisms in observed two-phase flows.

Keywords: Void fraction; Interfacial area concentration; Four-sensor probe; Interfacial area transport; Large diameter pipe 


\section{NOMENCLATURE}

$a_{i} \quad$ interfacial area concentration, $1 / \mathrm{m}$

$D \quad$ diameter of the pipe, $\mathrm{m}$

$C_{0} \quad$ distribution parameter, -

$D_{a v} \quad$ Average bubble diameter, $\mathrm{m}$

$D_{S m} \quad$ Sauter mean diameter, $m$

$D_{c, \max } \quad$ maximum diameter of cap bubbles, $\mathrm{m}$

$D_{d, \max } \quad$ maximum distorted bubble limit, $\mathrm{m}$

$g$ gravitational acceleration, $\mathrm{m} / \mathrm{s}^{2}$

j mixture volumetric flux, $\mathrm{m} / \mathrm{s}$

$j_{g} \quad$ superficial gas velocity, $\mathrm{m} / \mathrm{s}$

$j_{f} \quad$ superficial liquid velocity, $\mathrm{m} / \mathrm{s}$

$L_{c h, j} \quad$ axial bubble chord length of the $j$-th bubble, $\mathrm{m}$

$P \quad$ Pressure, $\mathrm{Pa}$

$R \quad$ radius of the pipe, $m$

$r \quad$ radial distance from the center of the pipe, $m$

$S_{B} \quad$ rate of change of bubble number density due to bubble breakup, $1 /\left(\mathrm{m}^{3} \mathrm{~s}\right)$

$S_{C} \quad$ rate of change of bubble number density due to bubble coalescence, $1 /\left(\mathrm{m}^{3} \mathrm{~s}\right)$

$S_{P} \quad$ rate of change of bubble number density due to phase change, $1 /\left(\mathrm{m}^{3} \mathrm{~s}\right)$

$t_{F j} \quad$ the times when the $j$-th bubble leaves the front sensor tip of a four-sensor probe

$t_{R j} \quad$ the times when the $j$-th bubble touches the front sensor tip of a four-sensor probe

$v_{f} \quad$ liquid velocity, $\mathrm{m} / \mathrm{s}$

$\widetilde{v}_{f} \quad$ liquid turbulence intensity, -

$v_{g} \quad$ interfacial velocity (=gas velocity), $\mathrm{m} / \mathrm{s}$

$V_{g j} \quad$ drift velocity, $\mathrm{m} / \mathrm{s}$

$z \quad$ height from the inlet of the pipe, $m$

\section{Greek Letters}

$\alpha \quad$ void fraction, -

$\rho_{f} \quad$ liquid phase density, $\mathrm{kg} / \mathrm{m}^{3}$

$\rho_{g} \quad$ gas phase density, $\mathrm{kg} / \mathrm{m}^{3}$

$\sigma \quad$ surface tension, $\mathrm{N} / \mathrm{m}$

$\xi \quad$ ratio of the $a_{i}$ change due to the bubble coalescence and breakup to the $a_{i}$ change due to the bubble expansion

$\Psi \quad$ a factor depending on the shape of the bubbles $(\Psi=1 /(36 \pi)$ for spherical bubbles $)$

\section{Subscripts}

$0 \quad$ inlet of the pipe

$1 \quad$ group 1 bubbles

2 group 2 bubbles 
$g \quad$ gas phase

$f \quad$ liquid phase

\section{Mathematical symbols}

$<\quad$ cross-sectional area-averaged quantity

$<<>\quad$ void fraction weighted cross-sectional area-averaged quantity

$<<\gg\rangle_{\mathrm{a}} \quad$ interfacial area concentration weighted cross-sectional area-averaged quantity 


\section{Introduction}

The two-fluid model is widely used in the analysis of various heat transfer systems, such as boilers, condensers, chemical reactors, and in particular, nuclear power reactors, for example, reactor safety analysis codes: RELAP5 (TRCDT, 1995) and TRACE (Odar et al., 2004). The two-fluid model is formulated by considering each phase separately in terms of two-sets of conservation equations which govern the balance of mass, momentum and energy of each phase. These balance equations represent the macroscopic fields of each phase and are obtained from proper averaging methods (Ishii, 1975; Ishii and Hibiki, 2010). Since the macroscopic fields of each phase are not independent of the other phase, the phase interaction terms which couple the transport of mass, momentum and energy of each phase appear in the field equation. It is expected that the two-fluid model can predict mechanical and thermal non-equilibrium between phases accurately. However, it is noted that the interfacial transfer terms should be modeled accurately for the two-fluid model to be useful. In the present state of the arts, the closure relations for these interfacial terms are the weakest link in the two-fluid model. The difficulties arise due to the complicated transfer mechanisms at the interfaces coupled with the motion and changing geometry of the interfaces.

The interfacial transfer terms are expressed in terms of interfacial area concentration $\left(a_{i}\right)$ and the driving potentials as (Ishii, 1975)

$$
\text { (Interfacial transfer term) } \approx a_{i} \times(\text { Driving potential). }
$$

The driving potentials for the interfacial transport characterize the local transport mechanisms such as the turbulence and molecular transport properties. The interfacial area concentration defined as the interfacial area per unit volume of the mixture characterizes the geometric capability of the interfacial transfer; therefore it must be related to the internal flow structures and evolution of the two-phase flow. Since the interfacial area concentration is an essential property for internal flow pattern of two-phase flow, it changes with the physical evolution of the flow. Therefore, the change of interfacial area concentration could be described by a transport equation, which is capable of closely modeling the two-phase flow evolution across flow regime transition boundaries (Ishii, 1975, Kocamustafaogullari and Ishii, 1995). The one-group interfacial area transport equation, developed by averaging the bubble size over the flow channel, has been applied to predicting the interfacial area transport in bubbly flows (Hibiki and Ishii, 2000a). The two-group interfacial area transport equations, developed by treating the bubbles in two groups, the spherical/distorted bubble 
group and the cap/slug bubble group, have been applied to predicting the interfacial area transport at bubbly-to-slug flow transition (Hibiki and Ishii, 2000b).

The two-phase flow in large diameter piping systems are often encountered in many industrial applications. The chemical and petroleum industries utilize the large-diameter-pipe bubble columns in fluidized bed applications and the large-diameter-pipe pumping systems respectively. In the nuclear industry, the two-phase flows are commonly found in hydraulically large channels. The natural circulating flow in the chimney region of ESBWR (Economic Simplified Boiling Water Reactor) is a typical example of the application of two-phase flow in a large diameter pipe to nuclear industry. The two-phase flow in a large diameter pipe is characterized by (1) the strong bubble-induced turbulence or local secondary flow with no typical slug bubbles, (2) the weak wall-peaking profile in the radial void fraction distribution, (3) the large drift velocity resulted from the cap bubbles with large volume, and (4) the gradual formation of the large cap bubbles and the gradual transition of the flow regimes due to the gradual increase in the collisions between bubbles along the flow. Ohnuki and Akimoto (2000) identified five types of flow regimes, namely, undisturbed bubbly, agitated bubbly, churn bubbly, churn slug and churn froth for the upward air-water bubbly flow in a vertical large diameter pipe $\left(D=0.2 \mathrm{~m}, z / D^{=61.5}\right)$. Schlegel et al.(2009) classified the flow into bubbly flow, cap bubbly flow and churn-turbulent flow, based on the void fraction signal obtained by using Electrical impedance void meters in a vertical large diameter pipe $(D=0.15 \mathrm{~m}, z / D=29.3)$. Shen et al. (2005a, 2010) reported the flows as the bubbly flow, churn flow and slug flow (namely the intermittently upward-flowing large coalescent cap bubble flow) in a vertical large diameter pipe $(D=0.2 \mathrm{~m}, \mathrm{z} / D=130)$. Even though considerable differences exist in their definitions of the flow regimes in a vertical large diameter pipe, it is generally agreed that the spherical/distorted bubble group exists in the bubbly flow and the strongly turbulent flows and the cap bubbles with large volume are gradually forming and prevailing in the bubbly-to-slug flow transition region in the two-phase flow in a vertical large diameter pipe.

In order to develop the source and sink terms of two-group interfacial area transport equations, it is necessary to obtain the accurate experimental data of the spherical/distorted bubble group and the cap/slug bubble group and to understand the mechanisms of bubble coalescence and disintegration in the two-phase flow in a vertical large diameter pipe. Literature surveys on the existing data sets taken in upward two-phase flow in a vertical large-diameter pipe are summarized in Table 1. The investigators have attempted to determine the source and sink terms by using these data sets. 
However, relatively short test sections $(z / D \leq 60)$ in Table 1 restrict the flow evolution and prevent the investigators from getting the whole pictures of the flow developments. Data taken in long test sections can be utilized to benchmark the applicability of the source and sink terms based on the data sets taken in the low $z / D$ regions. Based on existing data base, large diameter pipe effect on flow parameters is more enhanced at low liquid velocity conditions since bubble-induced local circulation plays an important role in characterizing the two-phase flow structure.

In view of these points, measurements of vertical upward air-water two-phase flow in a round pipe with an inner diameter of $200 \mathrm{~mm}$ and a length of $26,000 \mathrm{~mm}$ (maximum $z / D=130$ ) are performed at low liquid flow rate by using 3 four sensor optical probes. The data provide the necessary information on the time averaged local hydrodynamic parameters of the two-phase flow and can be used for the development of reliable constitutive relations which reflect the true transfer mechanisms in the bubbly-to-slug flow transition flow in the large diameter pipes.

\section{Experimental}

\subsection{Two-phase flow experiment}

The two-phase flow experiment was performed by using a flow loop installed at Large Scale Test Facility (LSTF) in Japan Atomic Energy Agency (JAEA) (Shen et al., 2010). Figure 1 shows the schematic diagram of the two-phase flow loop. The test section was a round pipe made of the stainless steel in the lower part for its solidity and the transparent acrylic resin in the upper part to enable flow observation. Its inner diameter and length were 200 and $26,000 \mathrm{~mm}$, respectively, and total $z / D$ of the test section was 130 . Air was supplied by a compressor and was introduced into a mixing chamber through a porous ring tube $(10 \mathrm{~mm}$ high and $\phi 74 \mathrm{~mm})$ with circumferentially-aligned $2 \times 80$ holes of $\phi 0.5 \mathrm{~mm}$ (see Fig. 1). The air and purified water were mixed in the mixing chamber and the mixture flowed upwards through the test section. After flowing through the test section, the air was released into the atmosphere through a separator (namely, the open upper reservoir tank), while the water was circulated by a centrifugal pump. The flow rates of the air and water were measured with 3 orifice flow meters and 2 Venturi flow meters, respectively. The accuracies of the gas orifice flow meters and the liquid Venturi flow meters were $\pm 0.5 \% \mathrm{FS}$ (full scale) and $\pm 0.1 \%$ FS respectively at ambient temperature of 0 to $55^{\circ} \mathrm{C}$. The water temperature change was within $1^{\circ} \mathrm{C}$ for each flow condition. The different flow conditions had different water temperatures and the minimum and maximum water temperatures among 
all flow conditions were $23.4^{\circ} \mathrm{C}$ and $33.6^{\circ} \mathrm{C}$ respectively. The water temperature influences on the flow may limit the comparability of Sauter diameter and interfacial area concentration to some extent. The local flow measurements using three four-sensor probes were performed at three axial locations of $z / D=41.5,82.8$ and 113 and 11 radial locations, i.e. $r / R=0.00,0.20,0.40,0.50,0.60,0.70,0.75,0.80,0.85,0.90,0.95 .8$ differential pressure (DP) gauges, whose maximum uncertainties were estimated as $\pm 0.1 \mathrm{kPa} / \mathrm{m}$, were installed along the flow in the test section to measure the area-averaged void fraction by neglecting their corresponding frictional pressure loss. The flow-meter-measured area-averaged superficial liquid velocities, $\left\langle j_{p}\right\rangle$, and the flow-meter-measured area-averaged superficial gas velocities at the inlet, $\left\langle j_{g}>\right.$, in this experiment were tabulated with their corresponding local pressures, $P$, and area-averaged void fractions, $<\alpha>$ in Table 2. The flow conditions covered bubbly to cap turbulent flow regimes and were shown in Fig. 2 .

\subsection{Instrumentation}

The optical four-sensor probes were utilized in the local measurements in present experiments. The working principle of an optical probe is based on the refraction and reflection laws in the optical fiber. A liquid-gas interface passing by the tip of the probe causes the laser light to change from one reflection state to another. Thus, the existence of liquid or gas around the optical fiber tip can be distinguished in a two-phase flow. Based on the basic working principle of the optical probe and the definition of various local two-phase flow parameters, the optical four-sensor probe can measure reliably the values of the time-averaged local void fraction $(\alpha)$, the time-averaged local interfacial area concentration $\left(a_{\mathrm{i}}\right)$, the average local gas velocity $\left(v_{\mathrm{g}}\right)$ and the time-averaged local Sauter mean diameter $\left(D_{S m}\right)$. The detailed measurement methods can be referred to the previous works (Kataoka et al., 1986, Shen et al., 2005b and Shen et al., 2008).

In order to verify the accuracy of the local four-sensor probe measurements, the area-averaged quantities obtained by integrating the local flow parameters over the flow channel were compared with those measured by other cross-calibration methods such as the differential pressure gauges for void fraction and the orifice flow meters for superficial gas velocity. The cross calibrations for area-averaged void fractions and superficial gas velocities were shown in Fig. 3. The area-averaged superficial gas velocities $\left\langle j_{g}>\right.$ from probes in Fig. 3 were calculated based on the local void fraction and local gas velocity measured by the four-sensor probe. The averaged and maximum relative 
deviations of the area-averaged void fractions between the four-sensor probe measurements and the differential pressure gauge measurements are $5.65 \%$ and $14.4 \%$ respectively. The averaged and maximum relative deviations of the superficial gas velocities between the four-sensor probe measurements and the orifice flow meter measurements are $18.8 \%$ and $36.9 \%$ respectively. So a good agreement has been reached in the present experiments.

There exist bubbles with different sizes and shapes, such as spherical, distorted, cap, slug, churn-turbulent bubbles, in generalized two-phase flow. These differences in bubble size and shape make substantial differences in their transport phenomena due to the differences in fluid particle interaction mechanisms such as drag force. In view of these differences, Kim et al. (2000) classified the bubbles into two groups, the spherical/distorted bubble group and the cap/slug bubble group, in terms of the maximum distorted bubble limit, $D_{d, \max }$, given by

$$
D_{d, \max }=4 \sqrt{\frac{\sigma}{g\left(\rho_{f}-\rho_{g}\right)}},
$$

where $\sigma, \rho_{f}, \rho_{g}$ and $g$ are the surface tension, the liquid phase density, the gas phase density and the gravitational acceleration respectively. Eq. (1) yields approximately $10 \mathrm{~mm}$ in an adiabatic air-water system under atmospheric conditions at $20^{\circ} \mathrm{C}$.

Following this classification, we categorized the bubbles and separated them into two groups, the spherical/distorted bubble group and the cap/slug bubble group, based on the comparison between the maximum distorted bubble limit and the axial bubble chord length of each bubble in the present experiment. The bubble-chord-length based categorization of the group 1 and 2 bubbles was originally proposed and confirmed in two-phase flow local measurement by Kim et al. (2000). The axial bubble chord length of the $j$-th bubble, $L_{c h, j}$, is measured by

$$
L_{c h, j}=v_{g} \times\left(t_{F j}-t_{R j}\right) .
$$

where $t_{R j}$ and $t_{F j}$ are the times when the $j$-th bubble touches and leaves the front sensor tip of a four-sensor probe, respectively.

The categorization of the group 1 and 2 bubbles enables the measurement of the local flow parameters (namely, void fraction, interfacial area concentration, gas velocity and Sauter mean diameter) in each bubble group by using its corresponding bubbles. 


\subsection{Experimental conditions}

In the present study, experiments of 9 flow conditions have been carried out. Table 2 showed the flow conditions in details and Fig. 2 presented them on a flow regime map. In the table, the local $\left\langle j_{g}>\right.$ values accompanied by its corresponding local pressure $(P)$ and the measured local void fraction were tabulated by each axial location $(z / D=41.5$, 82.8 and 113). In Fig. 2, the transition line from bubbly to slug flow identified by Mishima and Ishii (1984) were superimposed.

\section{Results and discussion}

\subsection{Flow regimes}

The present observation through high speed camera showed that there exist the bubbly flow, the cap turbulent flow and the transition between them. We refer to the flow with small-dispersed bubbles only moving upward along the main flow as bubbly flow, the chaotic flow with intermittently moving large cap bubbles accompanied by numerous small bubbles as cap turbulent flow and the flow between the bubbly flow and the cap turbulent flow as the transition in this paper. The flow regime change from the bubbly flow to the transition happens when the cap bubbles are formed. The flow regime change from the transition to the cap turbulent flow happens when the cap bubbles reach its maximum size. Since the dominant cap bubbles are forming and growing in the transition from bubbly flow to the cap turbulent flow, the transition corresponds to the flow regime transition from bubbly to slug in the two-phase flow in small diameter pipe ( $D$ is less than $100 \mathrm{~mm}$ ). When the hydraulic diameter of a two-phase flow channel reaches a certain size, slug bubbles bridging the entire diameter can no longer be sustained due to interfacial instability. For this reason Kataoka and Ishii (1987) defined the critical diameter of the pipe as

$$
D_{c, \max }=40 \sqrt{\frac{\sigma}{g\left(\rho_{f}-\rho_{g}\right)}},
$$

Sun et al (2004) pointed out that $D_{c, \max }$ can be used as the maximum diameter of a stable bubble. The present observation showed that it was close to the maximum size of cap bubbles, which corresponds to the flow regime change from the transition to the cap turbulent flow.

The flow regime map was shown in Fig. 2. In the two-phase flow of small diameter pipe the pipe size slug bubble is 
formed easily and the flow regime transition happens quickly within the flow region with a very short flowing distance. However, in low-liquid-flow-rate two-phase flow of large diameter pipe the large cap/slug bubble is gradually formed after the intensive processes of bubble coalescence and breakup within the flow region with a very long flowing distance and the flow regime transition from bubbly flow to the cap turbulent flow happens gradually. The local violently turbulent movement and local reverse circulations of liquid phase and small bubbles are frequently observed in the flow regime transition and cap turbulent flow in the large diameter pipe. The existence of turbulent liquid phase and violent small bubbles in the cap turbulent flow is due to the strong wake effect of the periodically flowing cap bubbles with large volume. It is the characteristic flow of two-phase flow in a large diameter pipe.

\subsection{Local flow parameters}

The local flow parameters at three axial locations of $z / D=41.5,82.8$ and 113 were obtained by the measurements of the three four-sensor probes. Figures 4-7 shows the experimental data at $z / D=41.5$ and 113 to depict the flow development along the flow direction. The figure columns from left to right show the measured flow parameters for all bubbles, group 1 (spherical/distorted) bubbles and group 2 (cap/slug) bubbles, respectively, and the figure rows from top to bottom indicate the measured flow parameters for $\left\langle j_{p}>=0.0505 \mathrm{~m} / \mathrm{s}, 0.194 \mathrm{~m} / \mathrm{s}\right.$ and $0.312 \mathrm{~m} / \mathrm{s}$, respectively, in each matrix of 9 figures. One-dimensional axial developments of these local flow parameters are illustrated in Figs. 8-11. The bubble number for the data processing at each measuring point is $3000 \sim 10000$ and the effective numbers for group 1 and 2 bubbles are 1000 6000 and 0 500 respectively. Hereinafter we present and discuss the characteristics of local measurement results.

\subsubsection{Void fraction}

Figure 4 (a) and (b) show the behavior of void fraction profiles measured at $z / D=41.5$ and 113 in this experiment. Figure 8 also shows the axial development of area-averaged void fraction, $\langle\alpha\rangle$, obtained by integrating local void fraction over the flow channel. The meanings of the symbols in Fig. 4 and 8 are given in Table 2. The characteristics of the measured void fraction and the flow features are summarized as follows.

\section{(1) Void fraction characteristics of all bubbles}

Although Serizawa and Kataoka (1988) classified the void fraction distribution pattern into four basic types of 
distributions, that is, "wall peak", "intermediate peak", "core peak" and "transition" in vertical small diameter pipe, the observed basic patterns of the radial void fraction distribution are power-law (namely "core peak") and flat radial profiles for all bubbles in the present vertical large diameter pipe. In view of the large $z / D$ in this experiment, the inlet effect on the radial void fraction profiles may be negligible. The power-law radial void fraction profiles at low liquid flow rate may be due to the motion of the large bubbles driven by the center-facing lateral lift force and the flat radial void fraction profiles may be due to the prevalence of small bubbles in the low void fraction flow conditions (Lucas et al., 2010, Tomiyama et al., 2002). The flat radial void fraction profile usually consist of a same void fraction profile of group 1 bubbles and a zero value void fraction profile of group 2 bubbles (such as for $<j_{p}=0.194 \mathrm{~m} / \mathrm{s}$ and $0.312 \mathrm{~m} / \mathrm{s}$ in Fig. 4 (a)). There are two constituent patterns for the power-law radial void fraction profiles in the vertical large diameter pipe. The first combination is a power-law radial void fraction profile of group 1 bubbles and a flat radial void fraction profile of group 2 bubbles (such as $\square$ for $\left\langle j_{\uparrow}\right\rangle=0.0505 \mathrm{~m} / \mathrm{s}, 0.194 \mathrm{~m} / \mathrm{s}$ and $0.312 \mathrm{~m} / \mathrm{s}$ in Fig. 4 (b)), and the second one is a power-law radial void fraction profile of group 1 bubbles and a power-law radial void fraction profile of group 2 bubbles (such as $\bigcirc$ and $\triangle$ for $<j p=0.0505 \mathrm{~m} / \mathrm{s}, 0.194 \mathrm{~m} / \mathrm{s}$ and $0.312 \mathrm{~m} / \mathrm{s}$ in Fig. 4 (b)).

\section{(2) Void fraction characteristics of group 2 cap bubbles}

Although group 2 cap bubbles are low in number, they play the dominant roles in determining the void distribution characteristics of the two-phase flow in the vertical large diameter pipe. In the flow conditions with a flat radial void fraction profile, no group 2 cap bubble was observed and the flow belongs to the typical bubbly flow. In the flow conditions with power-law radial void fraction profiles, the profile shapes become sharper as the $\left\langle j_{g}\right\rangle$ increases or the flow development. The formed group 2 cap bubbles usually migrate to the pipe center region along the flow due to the lateral lift force acting on the cap bubbles moving in a shear flow with radial velocity gradient (Tomiyama et al., 2002). And the corresponding power-law radial void fraction profile of group 1 spherical/distorted bubbles might also accelerate the bubble coalescence in the pipe center region. So the group 2 cap bubbles increase more quickly in the pipe core region than in the pipe wall region. The group 2 cap bubbles are increasing significantly as the $<j_{p}>$ decrease, the $\left\langle j_{g}>\right.$ increase and the flow development in the flow conditions with the power-law radial void fraction profiles. When the $\left\langle j_{p}>\right.$ decreases and the flow develops along the flow, the wake formed behind a bubble or the bubble-induced turbulence could mainly contribute to promotion of random collision between bubbles and wake entrainment, resulting 
in enhanced bubble coalescence. The fact that the liquid turbulence intensity increases with the decreasing $\left\langle j_{P}>\right.$ in two-phase flow with low liquid flow rate was shown by the hot-film anemometry measurement results of Serizawa et al. (1975) and Shawkat et al. (2008) in vertical pipes of $\phi 60 \mathrm{~mm}$ and $\phi 200 \mathrm{~mm}$ respectively. When the $\left\langle j_{g}>\right.$ increases, the bubble coalescence is enhanced because of the decreasing distance between bubbles and the increasing liquid turbulence.

\section{(3) $\underline{\text { Void fraction characteristics of group } 1 \text { spherical/distorted bubbles }}$}

Group 1 spherical/distorted bubbles showed a power-law radial void fraction profile and a flat radial void fraction profile in the vertical large diameter pipe. Although the superficial gas velocity was gradually augmented along the flow direction by the gas expansion due to the axial pressure reduction, the void fraction of group 1 spherical/distorted bubbles did not increase significantly along the flow since it is closely linked with the behaviors of the leading group 2 cap bubbles. The void fraction from the group 1 spherical/distorted bubbles is increasing with the $\left\langle j_{g}>\right.$ increase in the present experiments.

\section{(4) Void fraction characteristics of the flow development}

Local void fraction is usually augmented along the flow direction by the gas expansion due to the axial pressure reduction. But the tendency cannot be kept for the high $\left\langle j_{g}>\right.$ flow conditions in Fig. 8 and the pronounced power-law profile shape of void fraction in the high $\left\langle j_{g}>\right.$ did not keep getting steeper and steeper along the axial direction in Fig. 4. On the contrary, the void fraction decreases locally along the flow at some regions (see $\bigcirc$ and $\triangle$ at $z / D=41-82.8$ for $<j_{p}=0.0505 \mathrm{~m} / \mathrm{s}$ in Fig. 8). The reason for this phenomenon is due to the gradual formation and the gradual growth of the dominant group 2 cap/slug bubbles in the flow regime transition in the vertical large diameter pipe. Figure 8 shows that the $\left\langle\alpha_{1}>\right.$ decreases significantly and the $<\alpha_{2}>$ increases significantly along the flow in flow regime transitions. Figure 9 shows that the $\left\langle D_{S m 1}>\right.$ increases slightly and the $\left\langle D_{S m 2}>\right.$ increases greatly along the flow in flow regime transition. The formation and the growth of the dominant large group 2 cap bubbles cause the increase of average relative velocity between the two phases, resulting in the local decrease of the void fraction in flow regime transitions in the large diameter pipe. 
Figure 5 shows the behaviors of Sauter mean diameter profiles, corresponding to those of void fraction profiles in Fig.

4. Fig. 9 shows the axial development of area-averaged Sauter mean diameters, $\left\langle D_{S m}>\right.$, obtained by integrating local Sauter mean diameter over the cross-sectional area of the pipe. The meanings of the symbols in Fig. 5 and Fig. 9 are found in Table 2. The profiles and developments of Sauter mean diameter show the following features in the flow.

\section{(1) Sauter mean diameter profiles in the radial direction}

The Sauter mean diameter profiles are almost uniform along the channel radius for group 1 spherical/distorted bubbles and show core peaking distribution shapes for group 2 cap/slug bubbles. Since the bubble breakup is not marked as compared with the bubble coalescence at low liquid flow rate, the size of group 2 cap bubbles increase gradually with the flow by random collision and wake entrainment. And the formed group 2 cap bubbles have a tendency to transport to the channel center. Thus the group 2 cap bubbles keep their core peaking radial distribution shapes in both void fraction and Sauter mean diameter. The shapes of these profiles do not change significantly along the flow, although the $\left\langle j_{g}>\right.$ increases gradually along the flow direction due to the bubble expansion. It should be mentioned that although the group 2 cap bubbles were detected in some cases, they were small in number (2 30 group 2 bubbles). So not smooth data curves (see $\square<j_{p}>=0.194 \mathrm{~m} / \mathrm{s}$ in Fig. $5(\mathrm{~b})$ ) or only part data (see $\square<j_{p}>=0.312 \mathrm{~m} / \mathrm{s}$ in Fig. 5(b)) of the group 2 cap bubbles appeared in the radial direction.

\section{(2) Sauter mean diameter characteristics of the flow development}

The increase of Sauter mean diameter with the flow development was observed for all bubbles in the bubbly flow (see $<j_{p}>=0.194 \mathrm{~m} / \mathrm{s}$ and $0.312 \mathrm{~m} / \mathrm{s}$ in Fig. 9). But Sauter mean diameter of group 1 and 2 cap bubbles starts to decrease (see Fig. 9) when the flow regime transitions into the cap turbulent flow. The local Sauter mean diameter decreases of group 1 and 2 cap bubbles along the flow might be attributed to the violent movement of the group 2 cap bubbles in cap turbulent flow. The preceding large group 2 cap bubble induces intensive liquid turbulence in the pipe and the liquid turbulence might have enough energy to make the successive group 2 cap/slug bubbles unstable and further disintegrate. And the group 1 spherical/distorted bubbles entering the wake region of a leading cap bubble are agitated and disintegrated into smaller ones in the cap turbulent flow. 
Fig. 6 shows the behaviors of interfacial area concentration profiles, corresponding to those of void fraction profiles in Fig. 4. Fig. 10 also shows the axial development of area-averaged interfacial area concentrations, $\left\langle a_{i}\right\rangle$, obtained by integrating local interfacial area concentration over the cross-sectional area of the pipe. The meanings of the symbols in Fig. 6 and 10 are found in Table 2. The characteristics of the measured interfacial area concentrations are summarized as follows.

\section{(1) Interfacial area concentration profiles in the radial direction}

The observed patterns of the interfacial area concentration distribution in the radial direction are power-law (namely “core peak") and flat radial profiles for all bubbles in the present experiments. The interfacial area concentration profiles are expected to be similar to the void fraction profiles for the group 1 bubbles. Since the Sauter mean diameters of the group 1 bubbles $\left(D_{S m 1}\right)$ were almost uniform along the channel radius and their interfacial area concentrations are directly proportional to their void fraction, their interfacial area concentration profiles displayed the same behavior as their respective void fraction profiles. Since the formation and the growth of cap bubbles decrease the interfacial area concentration significantly, the group 2 cap bubble contribution in interfacial area concentration in Fig. 6 is much lower, in comparison with their corresponding contribution in void fraction in Fig. 4.

\section{(2) Interfacial area concentration characteristics of the flow development}

The interfacial area concentrations of all bubbles increase with the flow development at low $<j_{g}>$ and high $<j_{\rho}>$ flow conditions ( $\square$ and $\bigcirc$ ) in Fig. 10, since the gas phase expands along with the axial pressure reduction. However, when the formation and growth of the cap bubbles start in the transition, the interfacial area concentration of all bubbles begins to decrease along the flow. After the large cap bubbles reach their maximum size at a certain flow region, the flow enters the cap turbulent flow regime and the interfacial area concentration of all bubbles starts to increase with the flow development (see $\triangle$ in the downstream regions of $<\mathrm{j}_{\mathrm{f}}>=0.0505 \mathrm{~m} / \mathrm{s}$ and $0.194 \mathrm{~m} / \mathrm{s}$ in Fig. 10). Since the group 1 spherical/distorted bubbles make a major contribution to the interfacial area concentration of all bubbles and the interfacial area concentration of group 1 bubbles decreases in the transition and increases again in the cap turbulent flow, the interfacial area concentration of all bubbles shows the same evolving tendency. The formation and growth of the cap bubbles is usually realized by their coalescing with the group 1 spherical/distorted bubbles, which results in the group 1 bubbles decrease in number and in interfacial area concentration in the transition. However, as discussed in Section 
3.2.2, the intensive liquid turbulence induced by the group 2 cap bubble might also cause the disintegration of both group 1 and 2 bubbles in the cap turbulent flow. The effect results in the number and interfacial area concentration increase of the group 1 bubbles in the cap turbulent flow.

\section{(3) Effect of $\left\langle j_{q}>\right.$ and $<j_{p}>$ on interfacial area concentration data}

The interfacial area concentrations of both group 1 and 2 bubbles increase with the increasing $\left\langle j_{g}\right\rangle$. The increase in $<j_{g}>$ will increase the bubble number greatly and enhance the bubble coalescence discussed in Section 3.2.1. Although the decreasing $\left\langle j_{p}\right\rangle$ accelerated the bubble coalescence, no significant changes in interfacial area concentration were observed in the present small changing region of $\left\langle j_{p}>\right.$.

\subsubsection{Interfacial velocity}

Figure 7 shows the behaviors of local interfacial velocity profiles, corresponding to those of local void fraction profiles in Fig. 4. The local interfacial velocity at each radial position was obtained from the arithmetic mean of all interfacial velocities measured by the four-sensor probe. Figure 11 shows the axial development of one-dimensional void fraction weighted cross-sectional area-averaged interfacial velocity, $\left\langle<v_{g}\right\rangle>$, obtained as follows.

$$
\left\{\begin{array}{l}
\left\langle\left\langle v_{g}\right\rangle\right\rangle=\frac{\left\langle v_{g} \alpha\right\rangle}{\langle\alpha\rangle} \quad \text { for all bubbles } \\
\left\langle\left\langle v_{g k}\right\rangle\right\rangle=\frac{\left\langle v_{g k} \alpha_{k}\right\rangle}{\left\langle\alpha_{k}\right\rangle} \quad \text { for group } k \text { bubbles }(k=1,2)
\end{array}\right.
$$

The meanings of the symbols in Fig. 7 and 11 are found in Table 2. The characteristics of the measured interfacial velocities are indicated as follows.

\section{(1) Interfacial velocity profiles in the radial direction}

The interfacial velocity profiles of the bubbles show a power-law radial distribution for group 1 bubbles and a flat radial distribution for group 2 bubbles in flow. Since the group 1 bubbles have the absolute majority in number, they determine the radial interfacial velocity profiles of all bubbles. The increasing $\left\langle j_{g}\right\rangle$ and the flow development generally increase the interfacial velocities of both group 1 and 2 bubbles. For the flow at low $\left\langle j_{g}>\right.$ conditions, the power-law shapes of interfacial velocity become sharper (see in Fig. 7) along the flow by gas expansion and lateral bubble 
migration. For the flow at high $\left\langle j_{g}>\right.$ conditions, there is no significant change in their power-law shape with the flow development. But the interfacial velocities of both group 1 and 2 bubbles seem to keep the same values for different $<j_{g}>$ in the flow regime transition region (see $\bigcirc$ and $\triangle$ of $<j_{p}>=0.0505 \mathrm{~m} / \mathrm{s}$ and $0.194 \mathrm{~m} / \mathrm{s}$ in Fig. 7(a)).

\section{(2) Interfacial velocity characteristics of the flow development}

Figure 11 shows that the void fraction weighted cross-sectional area-averaged interfacial velocity, $\left\langle\left\langle v_{g}\right\rangle\right\rangle$, increases with the flow development. The formation and the growth of the group 2 cap bubbles greatly accelerated the relative velocity between the two phases and the increasing velocity of $\left\langle<v_{g}\right\rangle>$ along the flow.

\subsection{One-dimensional interfacial area transport}

The interfacial transfers are expected to be changed greatly by the happening of the bubble coalescence and breakup and the gas expansion due to the pressure reduction along the flow direction. The bubble coalescence and breakup is largely due to the existence of shear-induced liquid turbulence and bubble-induced liquid turbulence, which promote the interactions between bubbles, and between bubbles and eddies in the two-phase flow.

Since the bubble expansion due to the pressure reduction can be thought of as the source and sink term of the interfacial area transport, the effect of the bubble coalescence and breakup on the interfacial area transport should be extracted to understand the mechanism of the interfacial area transport due to the bubble coalescence and breakup as follows. Hibiki and Ishii $(2000 \mathrm{~b}, 2002)$ derived the one-dimensional and one-group interfacial area transport equation taking the gas expansion along the flow direction into account as

$$
\frac{\partial\left\langle a_{i}\right\rangle}{\partial t}+\frac{\partial}{\partial z}\left(\left\langle a_{i}\right\rangle\left\langle\left\langle v_{g}\right\rangle\right\rangle_{a}\right)=\frac{1}{3 \Psi}\left(\frac{\langle\alpha\rangle}{\left\langle a_{i}\right\rangle}\right)^{2}\left(\left\langle S_{B}\right\rangle-\left\langle S_{C}\right\rangle+\left\langle S_{P}\right\rangle\right)+\frac{2\left\langle a_{i}\right\rangle}{3\langle\alpha\rangle}\left\{\frac{\partial\langle\alpha\rangle}{\partial t}+\frac{\partial}{\partial z}\left(\langle\alpha\rangle\left\langle\left\langle v_{g}\right\rangle\right\rangle\right)\right\}
$$

where $a_{\mathrm{i}}, t, z, \Psi, \alpha, S_{B}, S_{C}$ and $S_{P}$ denote interfacial area concentration, time, axial position, a factor depending on the shape of the bubbles ( $\Psi=1 /(36 \pi)$ for spherical bubbles), void fraction, rate of change of bubble number density due to bubble breakup, rate of change of bubble number density due to bubble coalescence, and rate of change of bubble number density due to phase change, respectively. The brackets of $\diamond,\langle<\rangle_{\mathrm{a}}$ and $\langle<>$ mean the area-averaged quantity, the interfacial area concentration weighted cross-sectional area-averaged quantity, and the void fraction weighted cross-sectional area-averaged quantity, respectively. Eq. (5) can be simplified as follows on the assumptions 
of (i) no phase change and (ii) steady flow.

$$
\frac{d}{d z}\left(\left\langle a_{i}\right\rangle\left\langle\left\langle v_{g}\right\rangle\right\rangle_{a}\right)=\frac{1}{3 \Psi}\left(\frac{\langle\alpha\rangle}{\left\langle a_{i}\right\rangle}\right)^{2}\left(\left\langle S_{B}\right\rangle-\left\langle S_{C}\right\rangle\right)+\frac{2\left\langle a_{i}\right\rangle}{3\langle\alpha\rangle} \frac{d}{d z}\left(\langle\alpha\rangle\left\langle\left\langle v_{g}\right\rangle\right\rangle\right)
$$

The LHS term is total change in the interfacial area concentration. The first term on the RHS represents the change in the interfacial area concentration due to the bubble coalescence and breakup. For the steady-state fully developed flow condition, an equilibrium between bubble coalescence and breakup rates is reached and the rate of change of bubble number density due to bubble breakup is equal to the rate of change of bubble number density due to bubble coalescence (namely, $\left\langle S_{B}\right\rangle-\left\langle S_{C}\right\rangle=0$ ) in the flow. The second term on the RHS represents the change in the interfacial area concentration due to the bubble volume change (namely bubble expansion) in the flow direction. If the ratio of the first term on the RHS to the second term on the RHS is defined by a parameter, $\xi$, Eq. (6) can be changed into

$$
\xi=\frac{\frac{1}{3 \Psi}\left(\frac{\langle\alpha\rangle}{\left\langle a_{i}\right\rangle}\right)^{2}\left(\left\langle S_{B}\right\rangle-\left\langle S_{C}\right\rangle\right)}{\frac{2\left\langle a_{i}\right\rangle}{3\langle\alpha\rangle} \frac{d}{d z}\left(\langle\alpha\rangle\left\langle\left\langle v_{g}\right\rangle\right\rangle\right)}=\frac{\frac{d}{d z}\left(\left\langle a_{i}\right\rangle\left\langle\left\langle v_{g}\right\rangle\right\rangle_{a}\right)}{\frac{2\left\langle a_{i}\right\rangle}{3\langle\alpha\rangle} \frac{d}{d z}\left(\langle\alpha\rangle\left\langle\left\langle v_{g}\right\rangle\right\rangle\right)}-1 \approx \frac{\left\langle a_{i}\right\rangle\left\langle\left\langle v_{g}\right\rangle\right\rangle_{a}-\left\langle a_{i}\right\rangle_{0}\left(\left\langle\left\langle v_{g}\right\rangle\right\rangle_{a}\right)_{0}}{\frac{2\left\langle a_{i}\right\rangle}{3\langle\alpha\rangle}\left(\langle\alpha\rangle\left\langle\left\langle v_{g}\right\rangle\right\rangle-\langle\alpha\rangle_{0}\left\langle\left\langle v_{g}\right\rangle\right\rangle_{0}\right)}-1
$$

where $\langle\alpha\rangle_{0},\left\langle a_{i}\right\rangle_{0},\left\langle\left\langle v_{g}\right\rangle_{0}\right.$ and $\left(\left\langle<v_{g}\right\rangle_{\mathrm{a}}\right)_{0}$ are the inlet cross-sectional area-averaged void fraction, the inlet cross-sectional area-averaged interfacial area concentration, the inlet void fraction weighted cross-sectional area-averaged interfacial velocity and the inlet interfacial area concentration weighted cross-sectional area-averaged interfacial velocity respectively. The $\xi$ represents the net change in the interfacial area concentration due to the bubble coalescence and breakup, relative to the change rate in the interfacial area concentration due to the bubble expansion along the flow. $\bar{\xi} 0$ or $\xi<0$ implies that the bubble breakup or coalescence is dominant, respectively.

The net change in the interfacial area concentration due to the bubble coalescence and breakup, $\xi$, are plotted against z/D in Fig. 12. The meanings of the symbols in Fig. 12 are found in Table 2. It should be noted in Fig. 12 that the measured void fraction, interfacial area concentration and interfacial velocity at $z / D=41.5$ were taken as $\langle\alpha\rangle_{0},\left\langle a_{i}\right\rangle_{0}$, $\left\langle\left\langle v_{g}\right\rangle\right\rangle_{0}$ and $\left.\left(\left\langle<v_{g}\right\rangle\right\rangle_{\mathrm{a}}\right)_{0}$, respectively, and the measured $\langle\alpha\rangle,\left\langle a_{i}\right\rangle,\left\langle\left\langle v_{g}\right\rangle\right\rangle$ and $\left\langle\left\langle v_{g}\right\rangle\right\rangle_{\mathrm{a}}$ at $z / D=82.8$ and 113 were used in the calculation of $\xi$. From Fig. 12 we obtained the following results. 
(1) Although both coalescence and breakup of bubbles exist in the two-phase, the coalescence surpassed the breakup and was the dominant mechanism of the interfacial area transport in the transition from bubbly flow to cap turbulent flow and the cap turbulent flow since $\xi<0$ around the region of $z / D=82.8$. The systematic decrease and increase of the $\xi$ $(\xi<0)$ indicate the increase and decrease of the coalescence speed in the coalescence-dominant flow region.

(2) The coalescence and breakup at about $z / D=113$ would be in equilibrium state since the corresponding $\xi$ is close to zero. The bubbles grow up in size and become the large cap bubbles in the transition from bubbly flow to cap turbulent flow due to the coalescence dominant mechanism. The $\xi$ change from minus to zero in the region of $z / D=113$ showed that the mechanism of interfacial area change appeared to change from the bubble coalescence dominant state to the bubble coalescence and breakup equilibrium state in cap turbulent flow, in which the bubble expansion due to pressure reduction would be dominant mechanism for the interfacial area increase.

(3) The $\xi$ tends to decrease when the $<j_{g}>$ increases. It reveals that the bubble coalescence effect increases with the increasing $\left\langle j_{g}>\right.$.

(4) The $\xi$ generally decreases with the decreasing $\left\langle j_{P}\right.$. It reaches its minimum value at $\left\langle j_{p}\right\rangle=0.0505 \mathrm{~m} / \mathrm{s}$ in the flow regime transition region. The result falls into line with the discussion Section 3.2.1, when the $<j_{p}>$ decreases, the bubble coalescence enhances.

\section{Conclusions}

The experiments in a total of 9 flow conditions in bubbly flow, cap turbulent flow as well as their transition have been performed in a vertical large diameter pipe with $200 \mathrm{~mm}$ in inner diameter and $26 \mathrm{~m}$ in height under low liquid flow rate. The four sensor optical probes were used_for the local measurement at three axial locations of $z / D=41.5,82.8$ and 113 as well as 11 radial locations. The local void fraction, interfacial area concentration, interfacial velocity and Sauter mean diameter for both Group 1 spherical/distorted bubbles and Group 2 cap/slug bubbles were obtained from the local measurement by using the bubble-chord-length based categorization. In order to develop the interfacial transport model, the mechanisms on the radial profiles of local flow parameters and their axial developments were discussed in detail. The significant decrease in void faction and interfacial area concentration and the increase in Sauter mean diameter and interfacial velocity were observed when the gradual flow regime transition happened. The one-dimensional interfacial 
area transport due to the bubble coalescence and breakup was displayed by introducing its net change parameter in the interfacial area concentration. The bubble coalescence was found to be the dominant mechanism of the interfacial area transport in the flow regime transition. After the large cap bubbles reached their maximum size, the mechanism of the interfacial area transport appeared to change from the bubble coalescence dominant state to the bubble coalescence and breakup equilibrium state in cap turbulent flow. The data set obtained in this study are expected to be used for the development of reliable constitutive relations such as the interfacial area transport equation, which reflect the true transfer mechanisms in two-phase flow.

\section{Acknowledgements}

The research project was supported by the Grant-in-Aid for Scientific Research from the Ministry of Education, Science, Sport and Culture of Japan (Grant No.: 20560774). The authors would like to express their sincere appreciation for the devoted assistance in the experiments from Messrs. I. Ohtsu and T. Nishikizawa of JAEA and Mr. Yamada and his group of Nuclear Engineering Co. Ltd (NECO).

\section{References}

Hibiki, T., \& Ishii, M. 2000a. One-group interfacial area transport of bubbly flows in vertical round tubes. Int. J. Heat Mass Transfer 43(15), 2711-2726.

Hibiki, T., \& Ishii, M., 2000b. Two-group interfacial area transport equations at bubbly-to-slug flow transition. Nucl. Eng. Des. 202(1),39-76.

Hibiki, T., Ishii, M., 2002. Development of one-group interfacial area transport equation in bubbly flow systems. Int. J. Heat Mass Transfer 45(11), pp. 2351-2372.

Ishii, M. 1975, Thermo-fluid Dynamic Theory of Two-phase Flow. Eyrolles Paris, France.

Ishii, M., Hibiki, T., 2010, Thermo-fluid Dynamics of Two-Phase Flow, Springer.

Ishii, M., Sun, X., Kim, S., 2003. Modeling strategy of the source and sink terms in the two-group interfacial area transport equation, Annals of Nuclear Energy, 30 (13), 1309-1331.

Kataoka, I., Ishii, M., 1987. Drift-flux model for large diameter pipe and new correlation for pool void fraction. Int. J. 
Heat Mass Transf. 30, 1927-1939.

Kataoka, I., Ishii, M., Serizawa, A., 1986. Local formulation and measurements of interfacial area concentration in two-phase flow. Int. J. Multiphase Flow 12 (4), 505-529.

Kim S., Fu, X., Wang, X., Ishii, M., 2000. Development of the miniaturized four-sensor conductivity probe and the signal processing scheme. Int. J. Heat Mass Transfer 43 (22), 4101-4118.

Kocamustafaogullari, G. and Ishii, M. 1995. Foundation of the interfacial area transport equation and its closure relations, Int. J. Heat Mass Transfer 38 (3), 481-493.

Lucas, D., Beyer, M., Szalinski, L., Schutz P. 2010. A new database on the evolution of air-water flows along a large vertical pipe, Int. J. Therm. Sci. 49 (4), 664-674.

Mishima, K. and Ishii M., 1984. Flow Regime Transition Criteria for Upward Two-Phase Flow in Vertical Tubes. Int. J. Heat Mass Transfer, 27(5), 727-737.

Odar, F., Murray, C., Shumway, R., Bolander, M., Barber, D. and Mahaffy, J., 2004. TRACE V4.0 User's Manual, U.S. Nuclear Regulatory Commission, Office of Nuclear Regulatory Research, USA

Ohnuki, A. and Akimoto H., 2000. Experimental Study on Transition of Flow Pattern and Phase Distribution in Upward Air-Water Two-Phase Flow along a Large Vertical Pipe. Int. J. Multiphase Flow, 26(3), 367-386.

Prasser, H. M., 2007. Evolution of interfacial area concentration in a vertical air-water flow measured by wire-mesh sensors. Nucl. Eng. Des. 237 (15-17), 1608-1617.

Schlegel, J.P., Sawant, P., Paranjape, S., Ozar, B., Hibiki, T., Ishii, M., 2009. Void fraction and flow regime in adiabatic upward two-phase flow in large diameter vertical pipes, Nucl. Eng. Des. 239(12), 2864-2874.

Serizawa, A. and Kataoka I., 1988. Phase distribution in two-phase flow, in N. H. Afgan (ed.), Transient Phenomena in Multiphase Flow, Hemisphere, Washington, DC, pp. 179-224.

Serizawa, A., Kataoka I., Michiyoshi I., 1975. Turbulence structure of air-water bubbly flow-II Local properties, Int. J. Multiphase Flow, 2(3), 235-245.

Shawkat, M.,Ching C., Shoukri, M., 2008. Bubble and liquid turbulence characteristics of bubbly flow in a large diameter vertical pipe. Int. J. Multiphase Flow, 34(8), 767-785.

Shen, X., Mishima, K., Nakamura, H., 2005a. Two-phase phase distribution in a vertical large diameter pipe. Int. J. Heat 
Mass Transfer 48 (1), 211-225.

Shen, X., Saito, Y., Mishima, K., Nakamura, H., 2006. A study on the characteristics of upward air-water two-phase flow in a large pipe. Exp. Therm. Fluid Sci. 31, 21-36.

Shen, X., Saito, Y., Mishima, K., Nakamura, H., 2005b. Methodological improvement of an intrusive four-sensor probe for the multi-dimensional two-phase flow measurement. Int. J. Multiphase Flow, 31(5), 593-617.

Shen, X., Mishima, K., Nakamura, H., 2008. Error reduction, evaluation and correction for the intrusive optical four-sensor probe measurement in multi-dimensional two-phase flow. Int. J. Heat Mass Transfer, 51(3-4), 882-895.

Shen, X., Matsui, R., Mishima, K., Nakamura, H., 2010. Distribution parameter and drift velocity for two-phase flow in a large diameter pipe. Nucl. Eng. Des. 240(12), 3991-4000.

Smith, T. R., 2002. Two-group interfacial area transport equation in large diameter pipes. PhD thesis, Purdue University, West Lafayette, IN, USA

Sun, X., Kim, S., Ishii, M., Beus, S.G., 2004. Modeling of bubble coalescence and disintegration in confined upward two-phase flow. Nucl. Eng. Des. 230 (1-3), 3-26.

Sun, X., Smith, T. R., Kim, S., Ishi, M., Uhle, J., 2002. Interfacial area of bubbly flow in a relatively large diameter pipe. Exp. Therm. Fluid Sci. 27 (1), 97-109.

The RELAP5 Code Development Team (TRCDT), 1995. RELAP5/MOD3 Code Manual, Volume 1: Code Structure, System, Models and Solution Methods, NUREG/CR-5535 (also INEL-95/0174), Idaho National Engineering Laboratory, Idaho Falls, ID.

Tomiyama, A., Tamai, H., Zun, I., Hosokawa, S., 2002. Transverse migration of single bubbles in simple shear flows, Chem. Eng. Sci., 57 (11), 1845-1858.

Yoneda, K., Yasuo, A., Okawa, T., (2002). Flow structure and bubble characteristics of steam-water two-phase flow in a large-diameter pipe. Nucl. Eng. Des. 217 (3), 267-281.

Table and Figure Captions

Table 1 Existing data sets taken in upward two-phase flow in a vertical large-diameter pipe Table 2 Flow conditions in this experiment 
Fig. 1 Schematic of experimental apparatus.

Fig. 2 Experimental conditions and flow regime map.

Fig. 3 Cross calibrations for void fraction and superficial gas velocity

Fig. 4 Local void fraction profiles

Fig. 5 Local Sauter mean diameter profiles

Fig. 6 Local interfacial area concentration profiles

Fig. 7 Local interfacial velocity profiles

Fig. 8 Axial development of area-averaged void fraction

Fig. 9 Axial development of area-averaged Sauter mean diameter

Fig. 10 Axial development of area-averaged interfacial area concentration

Fig. 11 Axial development of void fraction weighted mean interfacial velocity

Fig. 12 Interfacial area transport due to bubble coalescence and breakup along flow direction 
Table 1 Existing data sets taken in upward two-phase flow in a vertical large-diameter pipe

\begin{tabular}{|c|c|c|c|c|c|c|c|c|c|c|}
\hline Investigators & $\begin{array}{c}\text { Geometry } \\
{[\mathrm{mm}]}\end{array}$ & $\begin{array}{c}\text { Gas/ } \\
\text { Liquid }\end{array}$ & $\begin{array}{l}z / D \\
{[-]}\end{array}$ & $\begin{array}{c}P \\
{[\mathrm{MPa}]}\end{array}$ & $\begin{array}{c}\left\langle j_{g}>\right. \\
{[\mathrm{m} / \mathrm{s}]}\end{array}$ & $\begin{array}{c}\left\langle j_{p}>\right. \\
{[\mathrm{m} / \mathrm{s}]}\end{array}$ & $\begin{array}{c}<a_{\mathrm{i}}> \\
{[1 / \mathrm{m}]}\end{array}$ & $\begin{array}{l}\text { Number } \\
\text { of } a_{\mathrm{i}} \text { data }\end{array}$ & Other parameters & Technique \\
\hline $\begin{array}{l}\text { Ohnuki \& } \\
\text { Akimoto(2000) }\end{array}$ & $\begin{array}{l}200 \quad \text { ID } \\
\text { pipe }\end{array}$ & $\begin{array}{l}\text { Air/ } \\
\text { Water }\end{array}$ & 12,60 & 0.1 & $0.03-4.7$ & 0.06-1.06 & N/A & 0 & $\begin{array}{l}\text { Flow regime map, } \\
\alpha, v_{g}, D_{\mathrm{av}}, v_{f}, \widetilde{v_{f}}\end{array}$ & $\begin{array}{l}\text { Double-sensor } \\
\text { probe and X-type } \\
\text { hot-film probe }\end{array}$ \\
\hline \multirow[t]{2}{*}{ Smith (2002) } & $\begin{array}{l}101.6 \quad \text { ID } \\
\text { pipe }\end{array}$ & $\begin{array}{l}\text { Air/ } \\
\text { Water }\end{array}$ & $5,20,30$ & 0.1 & $0.048-7.0$ & $0.058-2.0$ & $37.9-334$ & 19 & $\alpha, v_{g}, D_{\mathrm{SM}}$ & Four-sensor probe \\
\hline & $\begin{array}{l}152.44 \text { ID } \\
\text { pipe }\end{array}$ & $\begin{array}{l}\text { Air/ } \\
\text { Water }\end{array}$ & $4,11,18$ & 0.1 & $0.04-1.0$ & $0.05-1.0$ & $103-425$ & 12 & $\alpha, v_{g}, D_{\mathrm{SM}}$ & Four-sensor probe \\
\hline $\begin{array}{l}\text { Yoneda et al. } \\
(2002)\end{array}$ & $\begin{array}{l}155 \text { ID } \\
\text { pipe }\end{array}$ & $\begin{array}{l}\text { Steam/ } \\
\text { Water }\end{array}$ & $\begin{array}{l}0.48,2.42 \\
, 4.35 \\
\end{array}$ & $\begin{array}{l}0.5 \\
\text { (Max.) }\end{array}$ & $0.01-0.25$ & 0.21-0.59 & N/A & 0 & $\alpha, v_{g}, D_{\mathrm{SM}}$ & $\begin{array}{l}\text { Double-sensor } \\
\text { probe }\end{array}$ \\
\hline Sun et al.(2002) & $\begin{array}{l}101.6 \text { ID } \\
\text { pipe }\end{array}$ & $\begin{array}{l}\text { Air/ } \\
\text { Water }\end{array}$ & $3,18,33$ & 0.1 & $\begin{array}{l}0.048- \\
0.121\end{array}$ & $0.058-1.021$ & $50-200$ & 5 & $\alpha, v_{g}, D_{\mathrm{SM}}$ & Four-sensor probe \\
\hline $\begin{array}{l}\text { Shen et } \\
\text { al.(2006) }\end{array}$ & $\begin{array}{l}200 \quad \text { ID } \\
\text { pipe }\end{array}$ & $\begin{array}{l}\text { Air/ } \\
\text { Water }\end{array}$ & 12,60 & 0.1 & $\begin{array}{l}0.0322- \\
0.218\end{array}$ & $0.148-1.12$ & $30.7-171$ & 6 & $\alpha, v_{g}, D_{\mathrm{SM}}$ & Four-sensor probe \\
\hline Prasser (2007) & $\begin{array}{l}195 \\
\text { pipe }\end{array}$ & $\begin{array}{l}\text { Air/ } \\
\text { Water }\end{array}$ & $1.1-40$ & 0.1 & $\begin{array}{l}0.0094- \\
0.53\end{array}$ & 1.02 & $10-235$ & 5 & $\alpha, v_{g}, D_{\mathrm{av}}$ & Wire-mesh sensor \\
\hline $\begin{array}{l}\text { Shawkat et al. } \\
\text { (2008) }\end{array}$ & $\begin{array}{l}200 \quad \text { ID } \\
\text { pipe }\end{array}$ & $\begin{array}{l}\text { Air/ } \\
\text { Water }\end{array}$ & 43 & 0.1 & $\begin{array}{l}0.005- \\
0.18\end{array}$ & $0.2-0.68$ & N/A & 0 & $\alpha, v_{g}, D_{\mathrm{av}}, v_{f}, \widetilde{v_{f}}$ & $\begin{array}{l}\text { Double-sensor } \\
\text { probe and X-type } \\
\text { hot-film probe }\end{array}$ \\
\hline
\end{tabular}


Table 2 Flow conditions in this experiment

\begin{tabular}{|c|c|c|c|c|c|}
\hline \multirow[t]{2}{*}{$z / D[-]$} & \multirow[t]{2}{*}{$<j_{P}>[\mathrm{m} / \mathrm{s}]$} & & \multicolumn{3}{|c|}{ Symbols } \\
\hline & & & $\square$ & $\bigcirc$ & $\triangle$ \\
\hline \multirow{9}{*}{41.5} & \multirow{3}{*}{0.0505} & $<j_{g}>[\mathrm{m} / \mathrm{s}]$ & 0.0130 & 0.139 & 0.215 \\
\hline & & $P[\mathrm{MPa}]$ & 0.266 & 0.231 & 0.225 \\
\hline & & $<\alpha>[\%]$ & 0.0439 & 0.300 & 0.323 \\
\hline & \multirow{3}{*}{0.194} & $<j_{g}>[\mathrm{m} / \mathrm{s}]$ & 0.0127 & 0.138 & 0.203 \\
\hline & & $P[\mathrm{MPa}]$ & 0.274 & 0.236 & 0.238 \\
\hline & & $<\alpha>[\%]$ & 0.0270 & 0.242 & 0.313 \\
\hline & \multirow{3}{*}{0.312} & $<j_{g}>[\mathrm{m} / \mathrm{s}]$ & 0.0128 & 0.136 & 0.209 \\
\hline & & $P[\mathrm{MPa}]$ & 0.270 & 0.241 & 0.232 \\
\hline & & $<\alpha>[\%]$ & 0.0198 & 0.199 & 0.267 \\
\hline \multirow{9}{*}{82.8} & \multirow{3}{*}{0.0505} & $<j_{g}>[\mathrm{m} / \mathrm{s}]$ & 0.0183 & 0.185 & 0.286 \\
\hline & & $P[\mathrm{MPa}]$ & 0.190 & 0.173 & 0.169 \\
\hline & & $<\alpha>[\%]$ & 0.0589 & 0.251 & 0.301 \\
\hline & \multirow{3}{*}{0.194} & $<j_{g}>[\mathrm{m} / \mathrm{s}]$ & 0.0177 & 0.187 & 0.267 \\
\hline & & $P[\mathrm{MPa}]$ & 0.196 & 0.175 & 0.181 \\
\hline & & $<\alpha>[\%]$ & 0.0369 & 0.234 & 0.283 \\
\hline & \multirow{3}{*}{0.312} & $<j_{g}>[\mathrm{m} / \mathrm{s}]$ & 0.0180 & 0.185 & 0.280 \\
\hline & & $P[\mathrm{MPa}]$ & 0.192 & 0.177 & 0.174 \\
\hline & & $<\alpha>[\%]$ & 0.0281 & 0.205 & 0.263 \\
\hline \multirow{9}{*}{113} & \multirow{3}{*}{0.0505} & $<j_{g}>[\mathrm{m} / \mathrm{s}]$ & 0.0255 & 0.246 & 0.373 \\
\hline & & $P[\mathrm{MPa}]$ & 0.135 & 0.129 & 0.129 \\
\hline & & $<\alpha>[\%]$ & 0.0798 & 0.267 & 0.326 \\
\hline & \multirow{3}{*}{0.194} & $<j_{g}>[\mathrm{m} / \mathrm{s}]$ & 0.0247 & 0.250 & 0.346 \\
\hline & & $P[\mathrm{MPa}]$ & 0.141 & 0.130 & 0.140 \\
\hline & & $<\alpha>[\%]$ & 0.0509 & 0.234 & 0.292 \\
\hline & \multirow{3}{*}{0.312} & $<j_{g}>[\mathrm{m} / \mathrm{s}]$ & 0.0254 & 0.249 & 0.372 \\
\hline & & $P[\mathrm{MPa}]$ & 0.135 & 0.130 & 0.131 \\
\hline & & $<\alpha>[\%]$ & 0.0390 & 0.212 & 0.269 \\
\hline
\end{tabular}




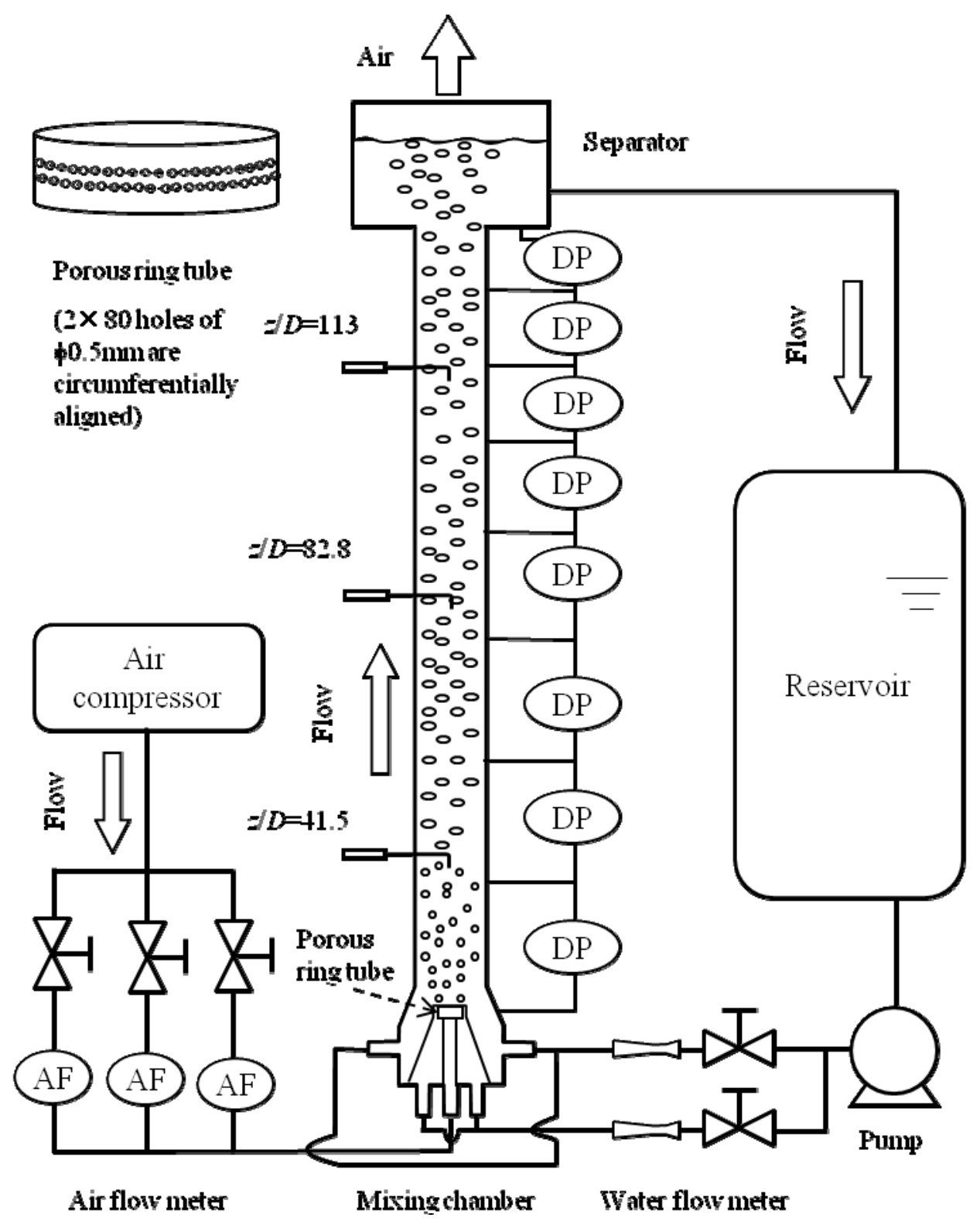

Fig. 1 Schematic of experimental apparatus. 


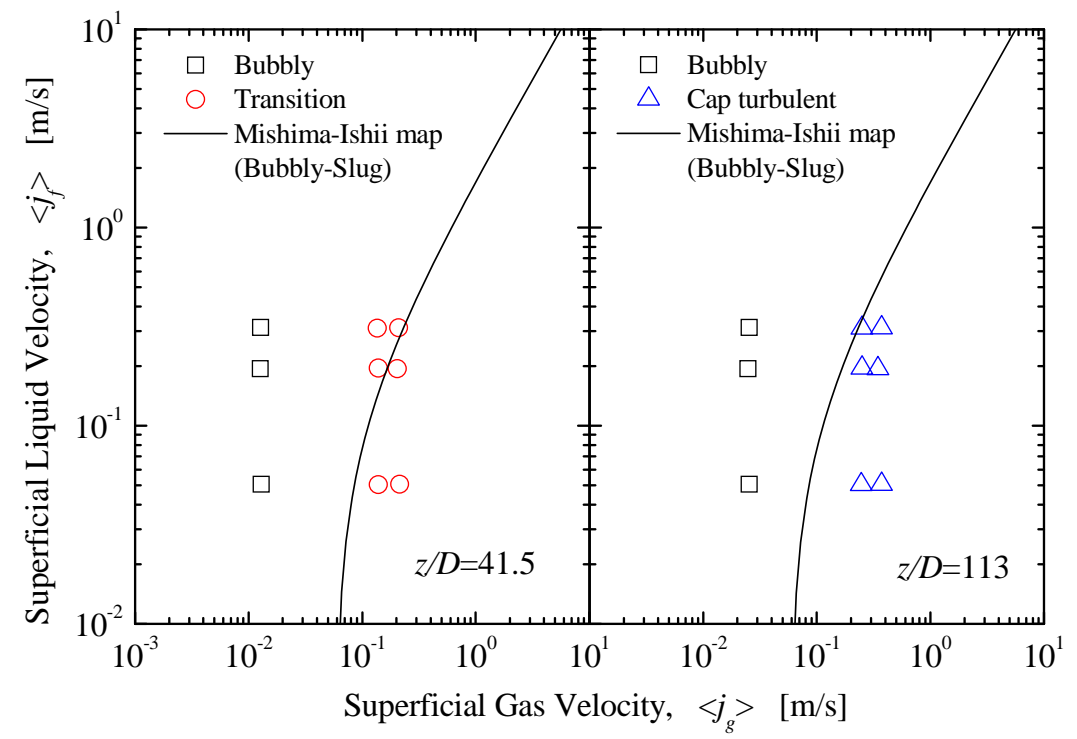

Fig. 2 Experimental conditions and flow regime map. 

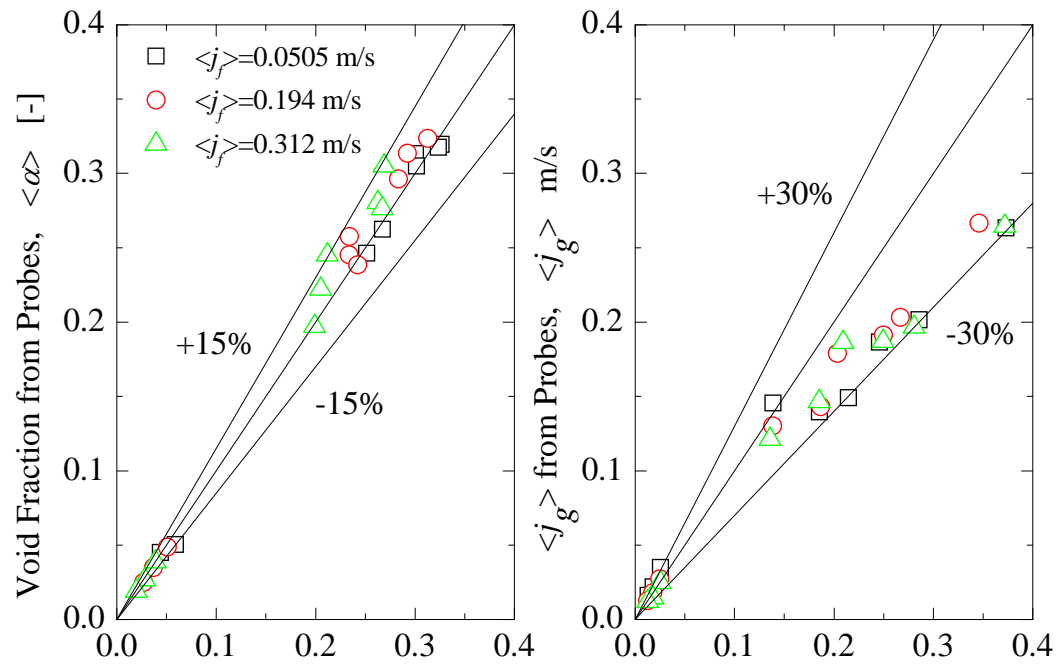

Void Fraction from DP, $<\alpha>[-] \quad<j_{g}>$ from Flow Meters, $\quad\left\langle j_{g}>\mathrm{m} / \mathrm{s}\right.$

Fig. 3 Cross calibrations for void fraction and superficial gas velocity 


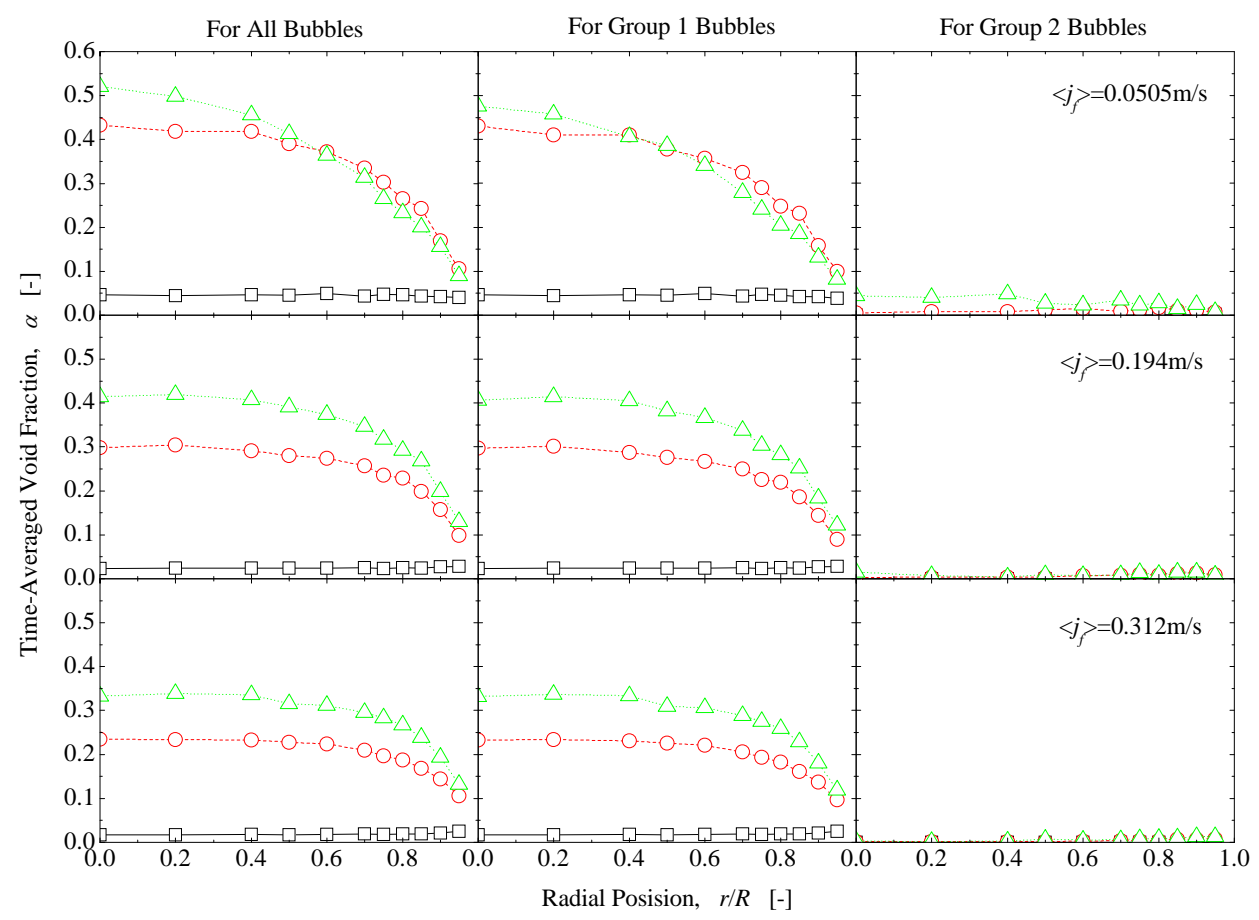

(a) At $z / D=41.5$

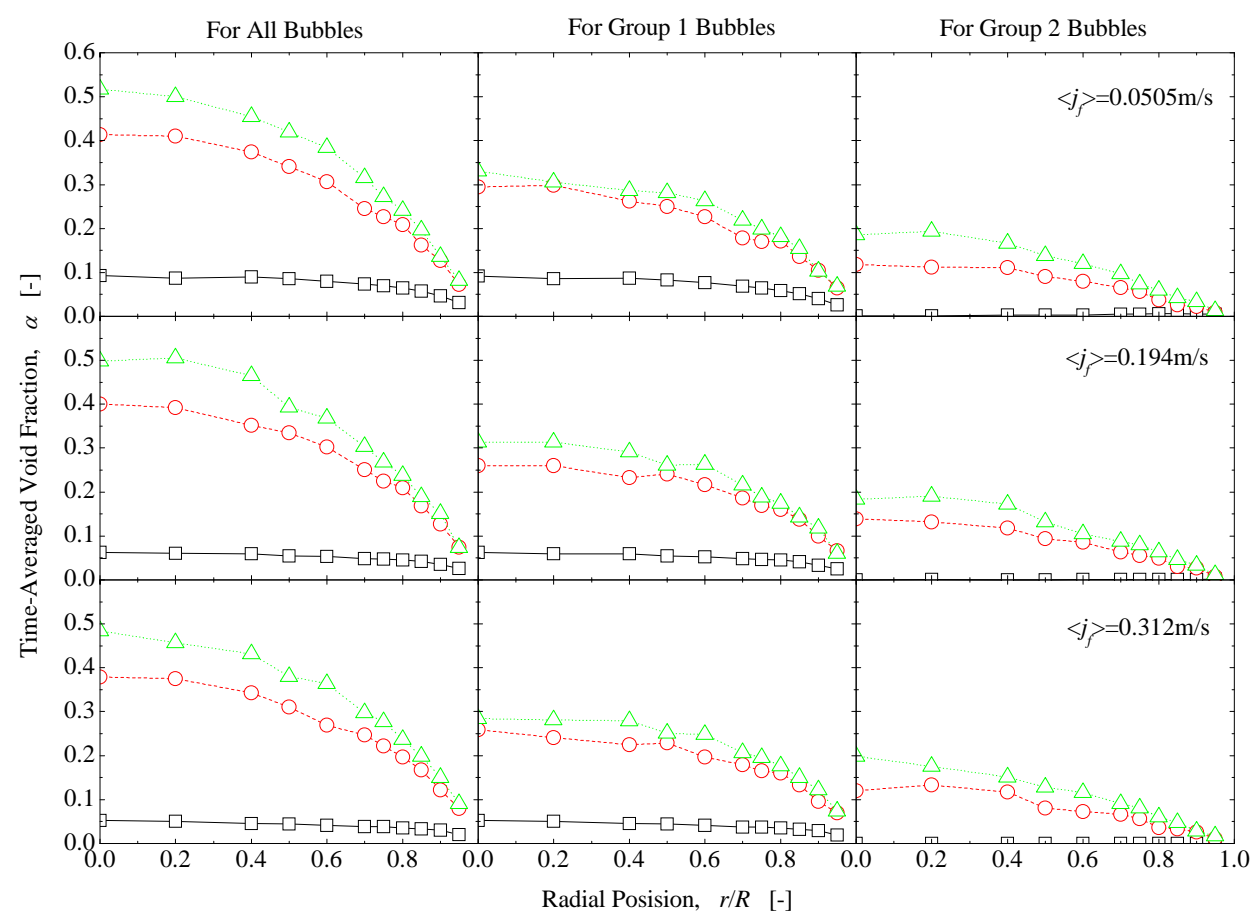

(b) At $z / D=113$

Fig. 4 Local void fraction profiles 


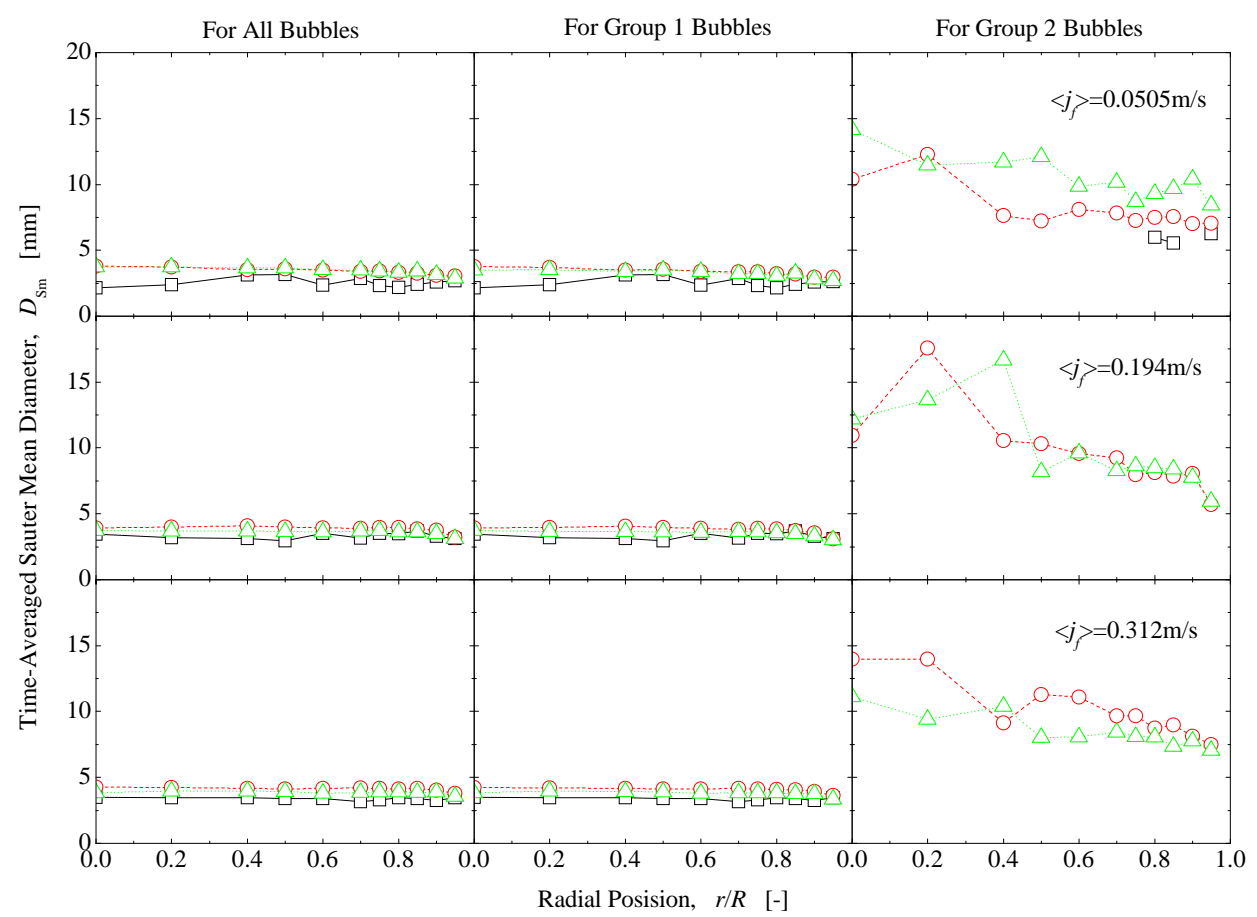

(a) At $z / D=41.5$

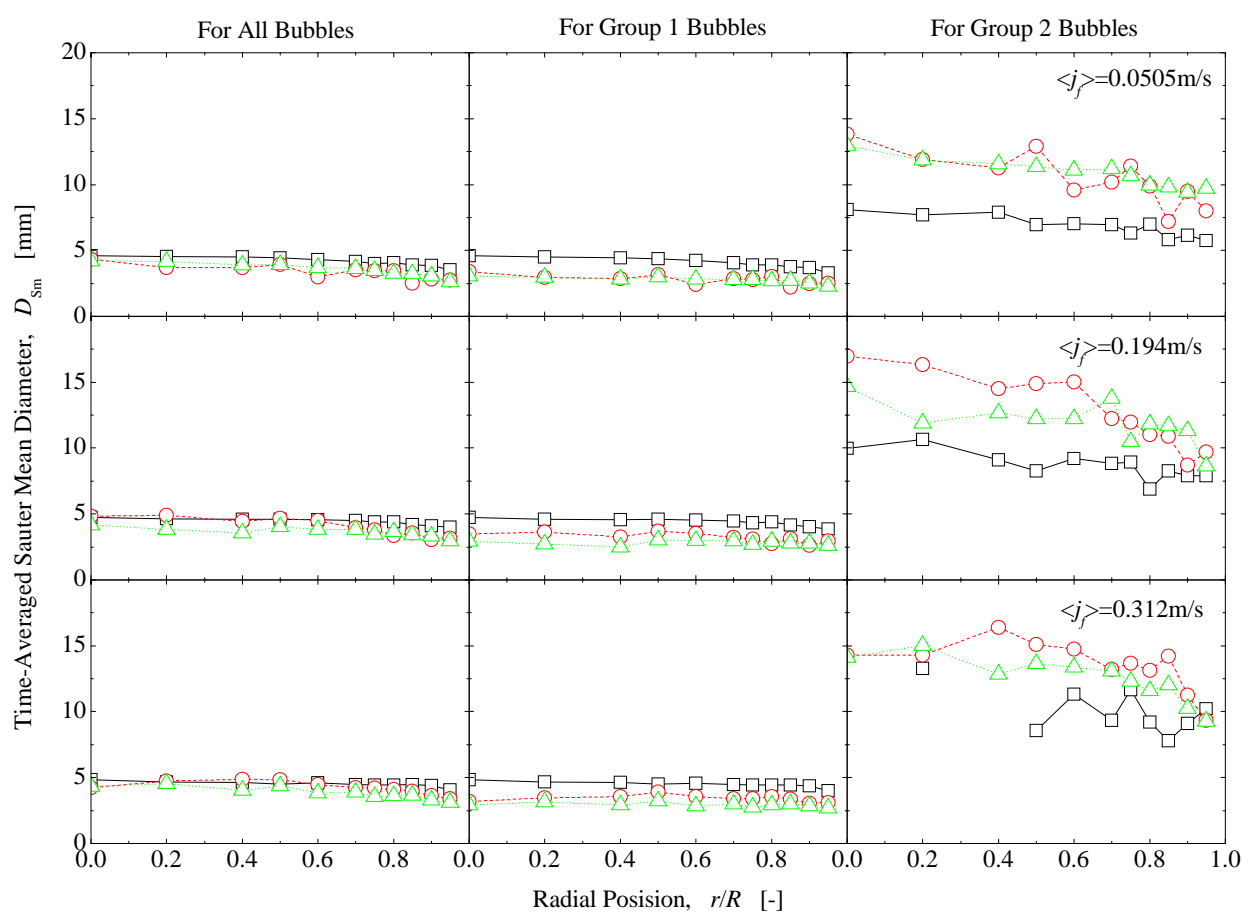

(b) At $z / D=113$

Fig. 5 Local Sauter mean diameter profiles 


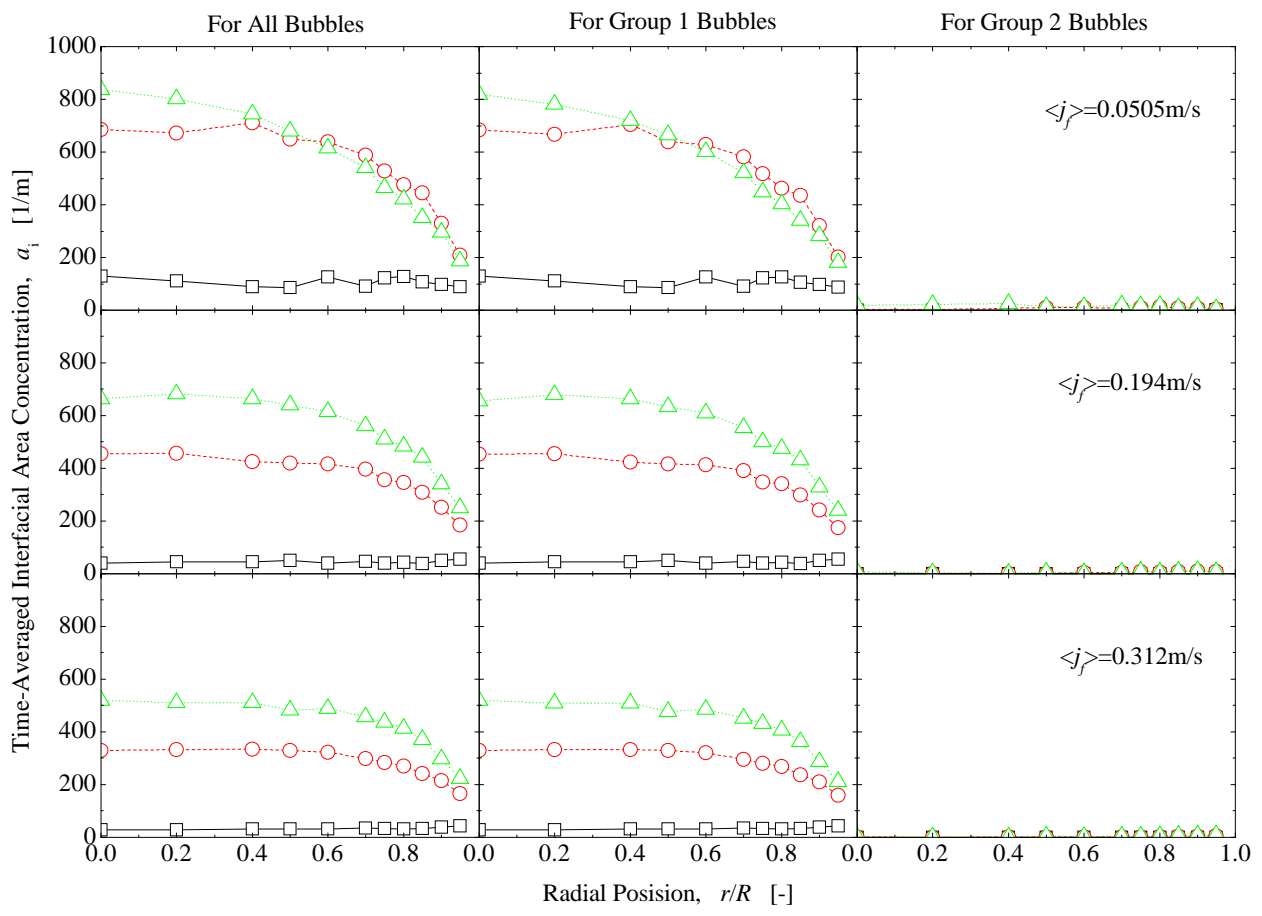

(a) At $z / D=41.5$

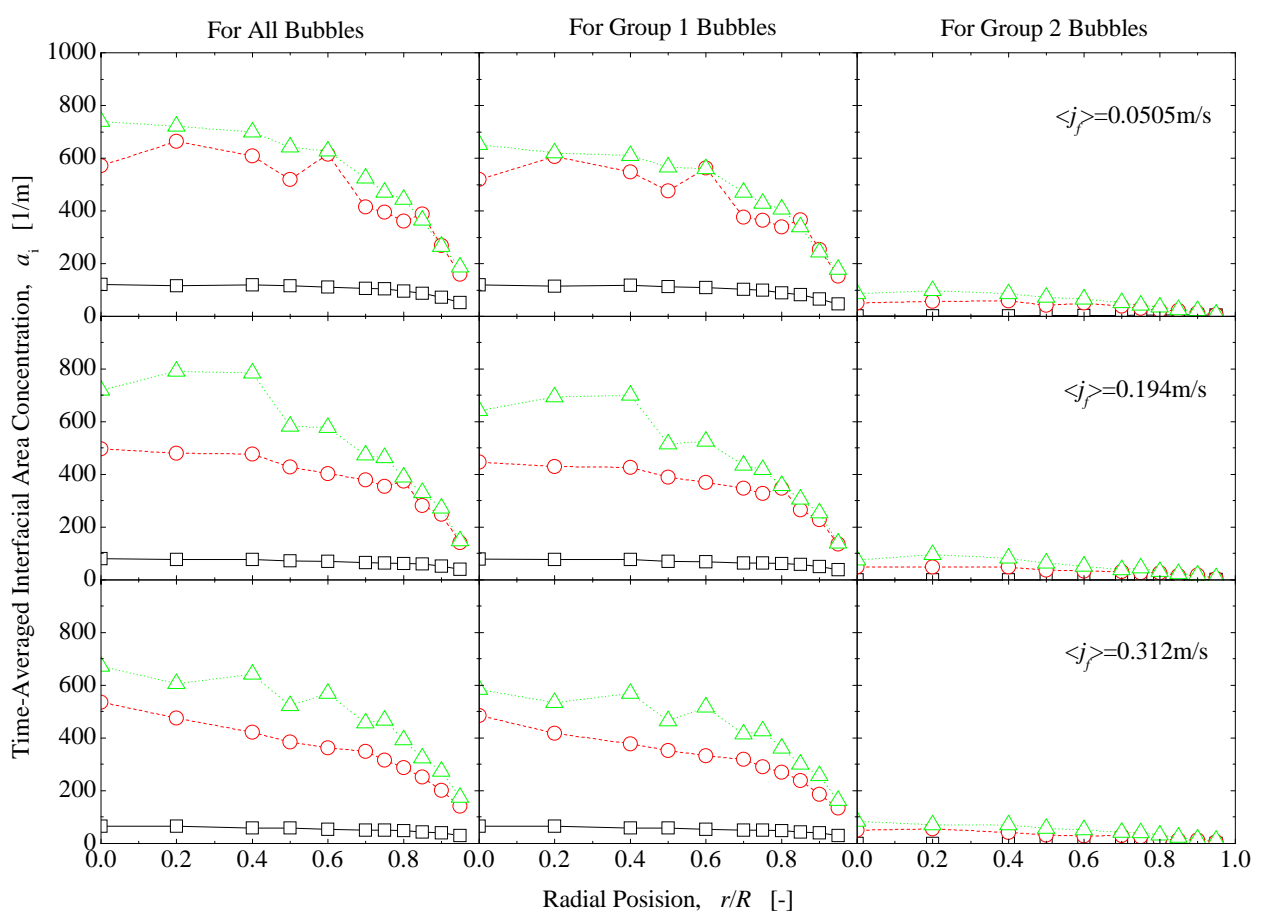

(b) At $z / D=113$

Fig. 6 Local interfacial area concentration profiles 


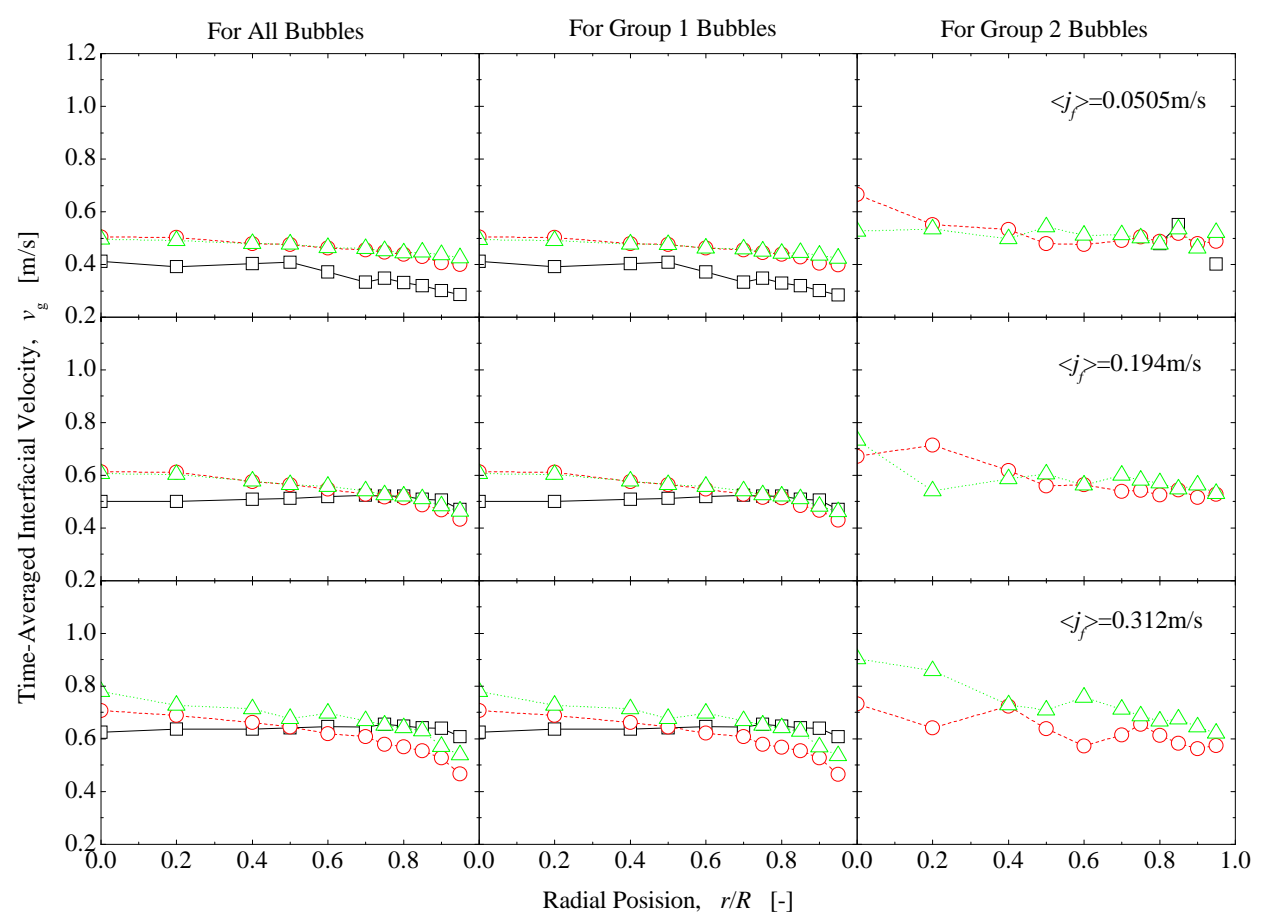

(a) At $z / D=41.5$

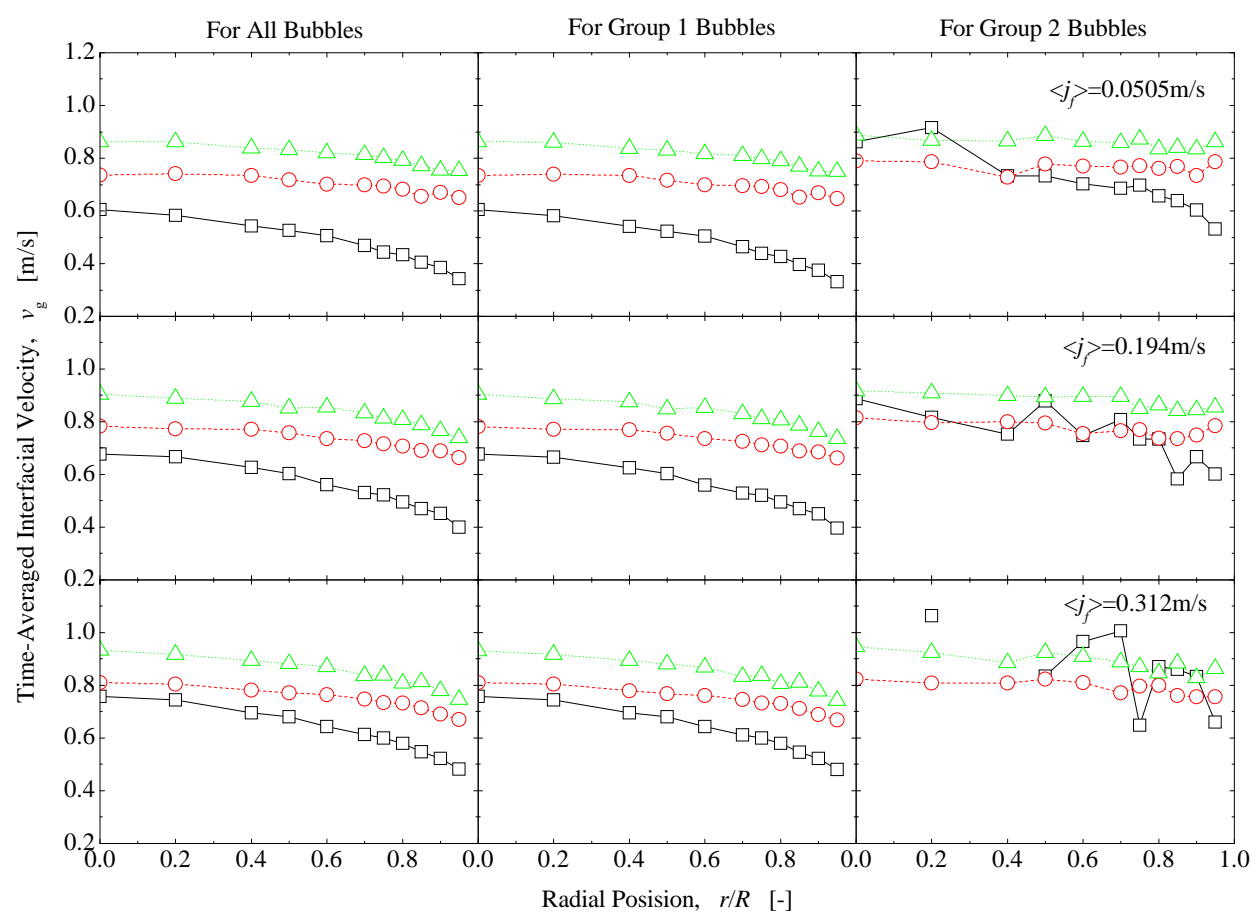

(b) At $z / D=113$

Fig. 7 Local interfacial velocity profiles 


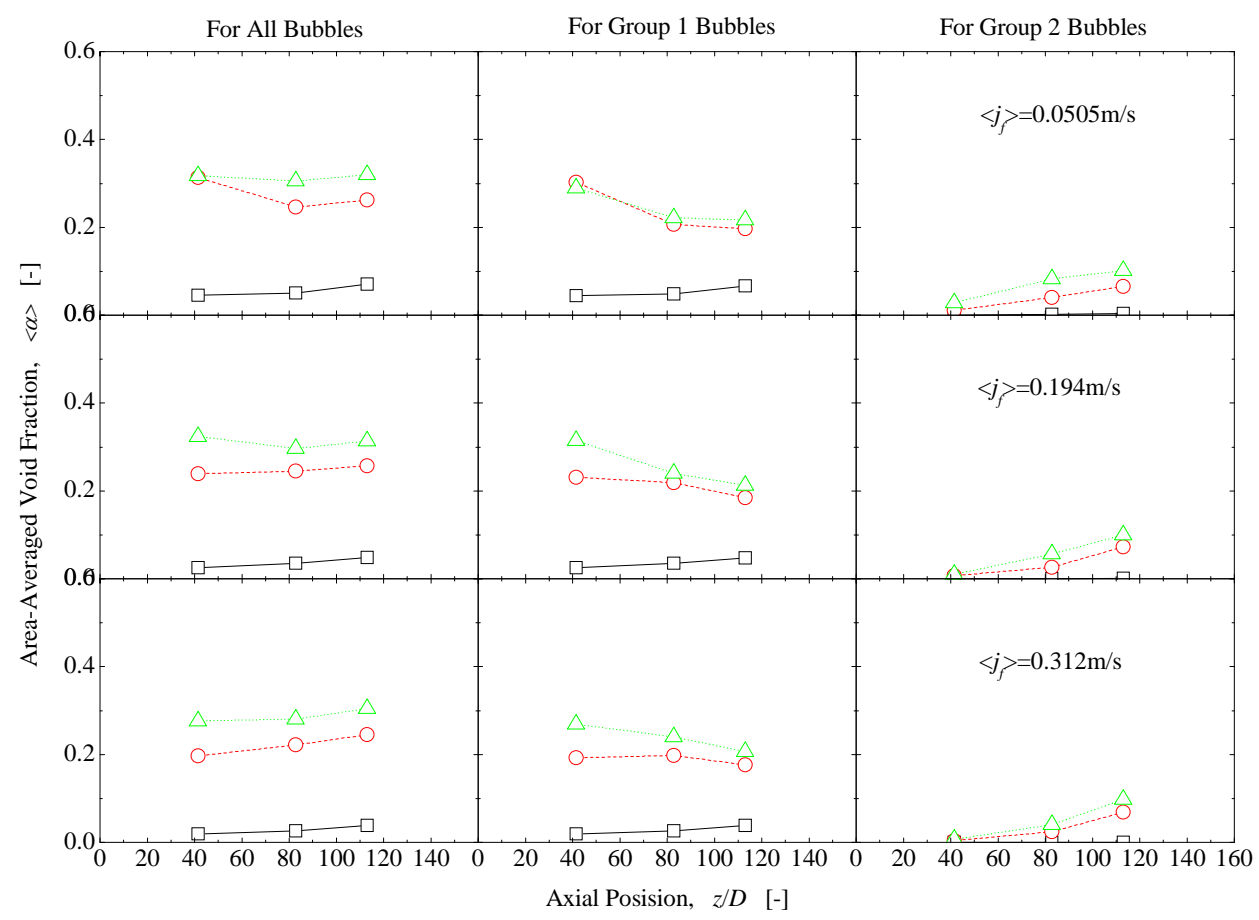

Fig. 8 Axial development of area-averaged void fraction 


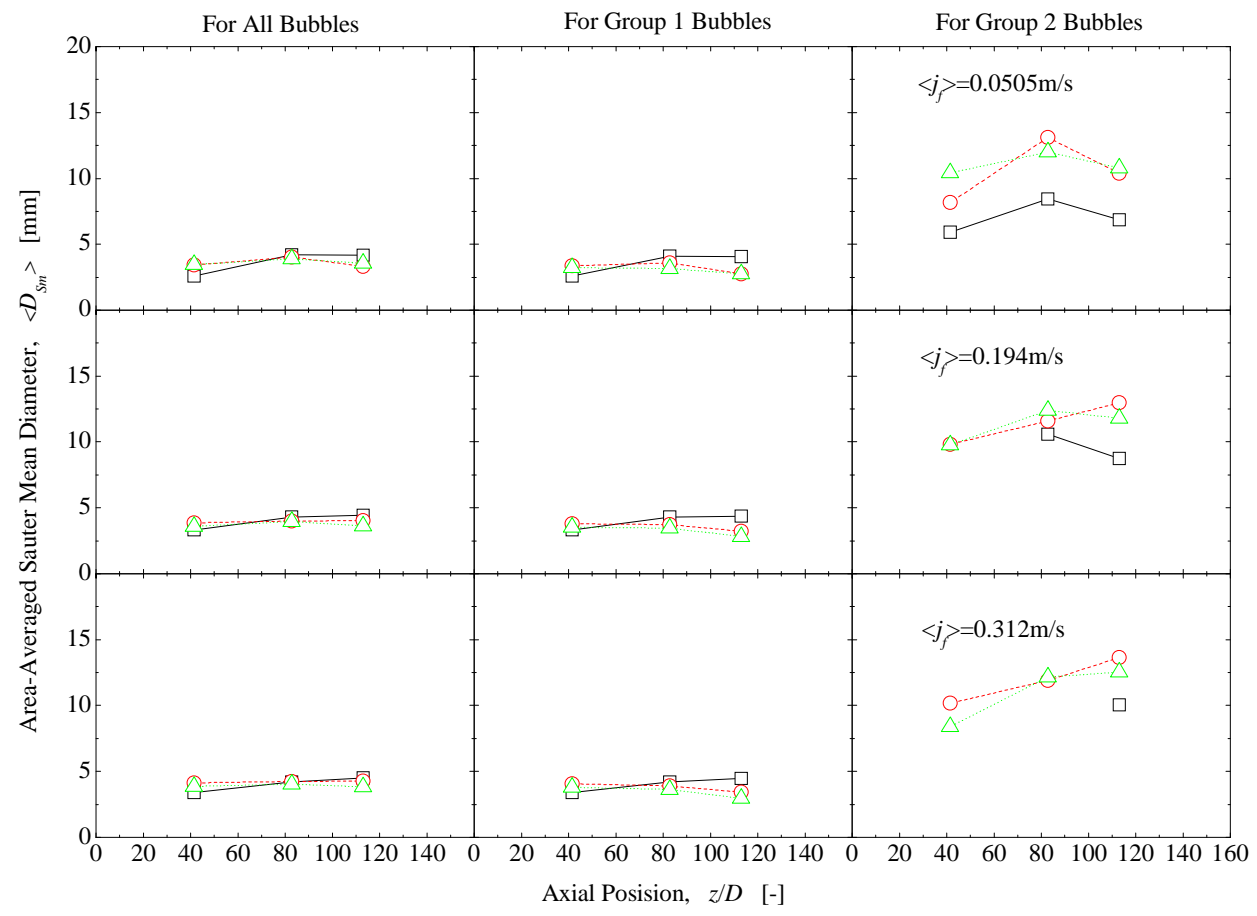

Fig. 9 Axial development of area-averaged Sauter mean diameter 


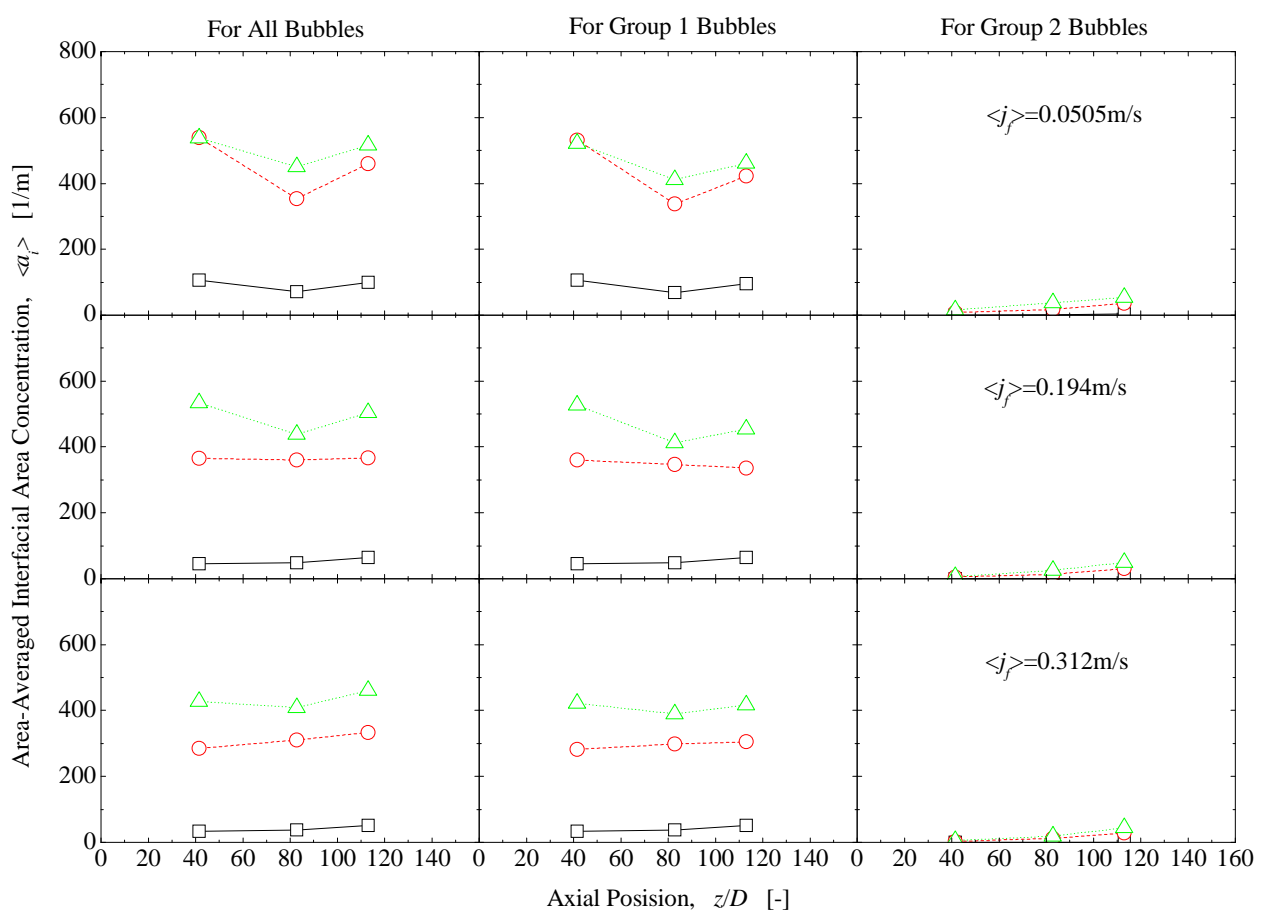

Fig. 10 Axial development of area-averaged interfacial area concentration 


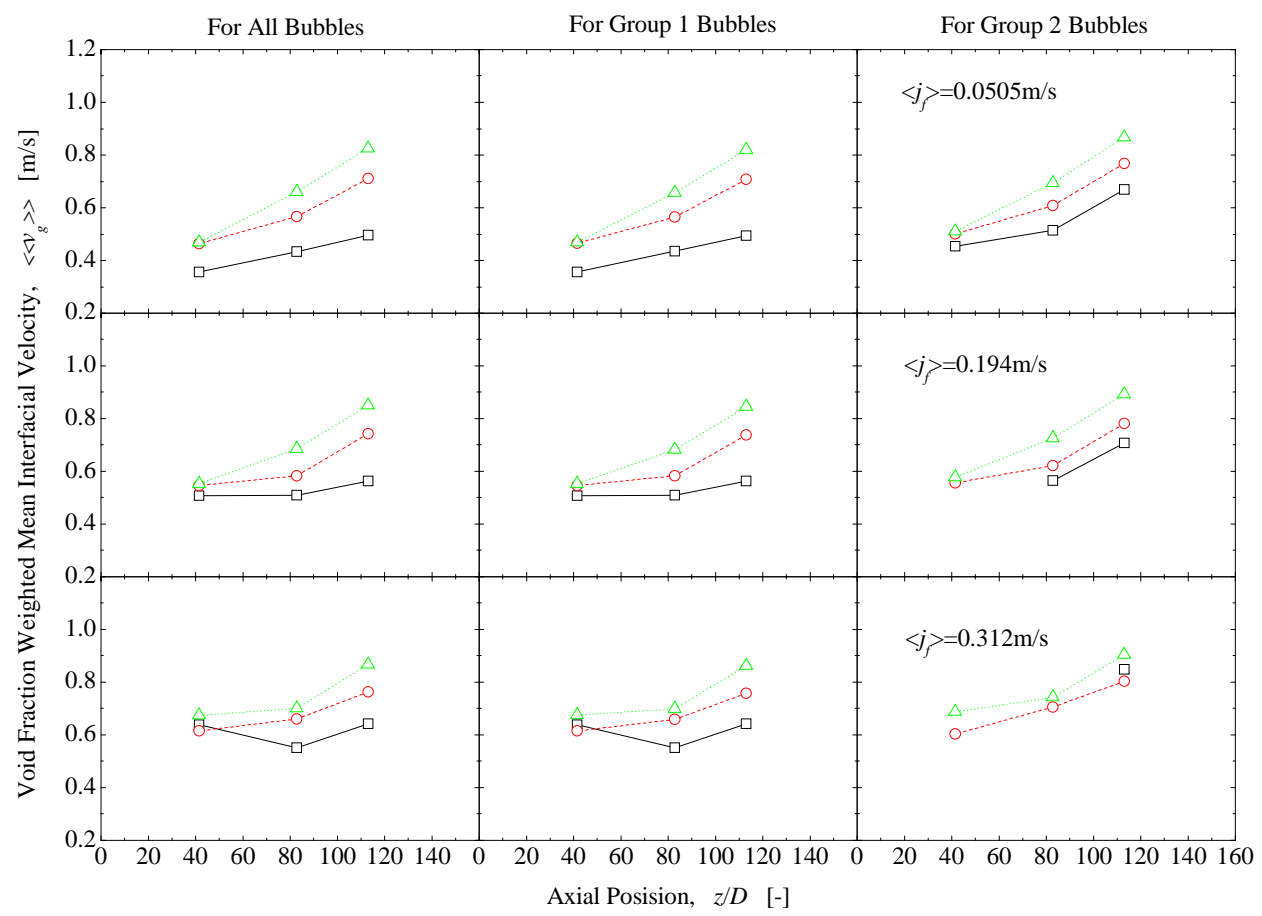

Fig. 11 Axial development of void fraction weighted mean Interfacial velocity 


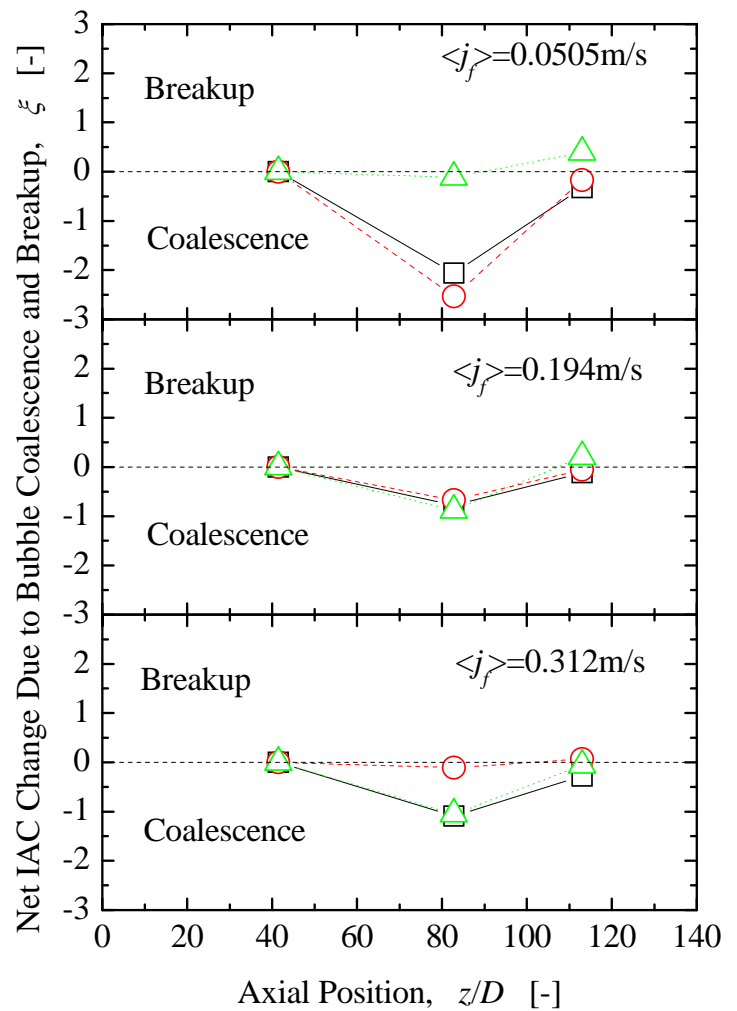

Fig. 12 Interfacial area transport due to bubble coalescence and breakup along flow direction 